\title{
The Genetic Basis of Graves' Disease
}

\author{
Rafał Płoski*,1, Konrad Szymański ${ }^{1}$ and Tomasz Bednarczuk*,2,3 \\ ${ }^{1}$ Department of Medical Genetics, Centre for Biostructure, Medical University of Warsaw, Poland \\ ${ }^{2}$ Department of Internal Medicine and Endocrinology, Medical University of Warsaw, Warsaw, Poland \\ ${ }^{3}$ Endocrinology Unit, Mossakowski Medical Research Centre Polish Academy of Sciences, Warsaw, Poland
}

\begin{abstract}
The presented comprehensive review of current knowledge about genetic factors predisposing to Graves' disease (GD) put emphasis on functional significance of observed associations. In particular, we discuss recent efforts aimed at refining diseases associations found within the HLA complex and implicating HLA class I as well as HLADPB1 loci. We summarize data regarding non-HLA genes such as PTPN22, CTLA4, CD40, TSHR and TG which have been extensively studied in respect to their role in GD. We review recent findings implicating variants of $F C R L 3$ (gene for FC receptor-like-3 protein), SCGB3A2 (gene for secretory uteroglobin-related protein 1- UGRP1) as well as other unverified possible candidate genes for GD selected through their documented association with type 1 diabetes mellitus: Tenr-IL2-IL21, CAPSL (encoding calcyphosine-like protein), IFIH1 (gene for interferon-induced helicase C domain 1), $A F F 3, C D 226$ and PTPN2. We also review reports on association of skewed $\mathrm{X}$ chromosome inactivation and fetal microchimerism with GD. Finally we discuss issues of genotype-phenotype correlations in GD.
\end{abstract}

Received on: May 31, 2011 - Revised on: August 05, 2011 - Accepted on: August 15, 2011

Keywords: Graves' disease, thyroid, autoimmunity, association, HLA, non-HLA genes.

\section{EARLY EVIDENCE FOR GENETIC PREDISPOSI- TION TO GRAVES' DISEASE - FAMILY STUDIES}

Graves' disease (GD) is an autoimmune disorder in which antibodies activate the thyrotropin receptor (TSHR) causing a hyperfunction of the thyroid gland. This activation stimulates follicular hypertrophy and hyperplasia, leading to thyroid enlargement and increases thyroid hormone production. GD affects approximately $0.5-2 \%$ of the Caucasian population and is the cause of the majority of cases of hyperthyroidism.

The familial occurrence of autoimmunological thyroid disorders (AITD) has been noticed a relatively long time ago when it was reported that a third of siblings of GD patients developed AITD and over half of asymptomatic children had thyroid antibodies in their blood [1]. Similar observations were made when examining patients with Graves' ophthalmopathy (GO), of which $36 \%$ had a first- or seconddegree relative affected with GD or other AITDs [2].

Perhaps the most convincing evidence for genetic predisposition to the disease is provided by twin studies. While in monogenic diseases there is a full concordance among monozygotic (MZ) twins, in disorders with complex inheritance the concordance is incomplete, but still higher compared to dizygotic (DZ) twins. Such observations were

*Address correspondence to these authors at the Department of Internal Medicine and Endocrinology, Medical University of Warsaw, ul. Banacha 1A, 02-097 Warsaw, Poland; Tel: +48 22599 2975; Fax: +48 22599 1975; E-mail: tbednarczuk@wum.edu.pl

Department of Medical Genetics, Centre of Biostructure, Medical University of Warsaw, ul. Pawinskiego 3C, 02-106 Warsaw, Poland; Tel: + 4822572 0695; Fax: + 4822572 0696; E-mail: rploski@wp.pl made in several twin studies of GD. In the Dutch twin cohorts the probandwise concordance rates were 0.36 and 0.03 for MZ and DZ pairs, respectively [3]. Model-fitting analysis of these data showed that $79 \%$ of the predisposition to the development of GD is attributable to genetic factors whereas individual specific environmental factors not shared by the twins could explain the remaining $21 \%[3,4]$. The results obtained during extensive American twin studies indicated that the estimated pairwise concordance for GD is 0.17 in MZ twins and 0.02 in DZ siblings [5] suggesting a smaller contribution of genes for GD development in American vs. European population.

Family and twin studies clearly demonstrated that GD is not caused by a single gene defect but has a complex pattern of inheritance [6,7]. Today it is clear that genetic predisposition to GD is accounted for by multiple genes with very modest individual effects. The majority of already identified loci confer only low risk for disease $(\sim 1.2-1.5)$ and it is likely that loci with even weaker effects will be discovered in the future.

\section{METHODOLOGICAL APPROACHES USED FOR IDENTIFYING GENETIC VARIANTS PREDISPOSI- NG TO GD}

The main methodological approaches used for studying genetic predisposition to GD are based on linkage or association analysis.

\section{Linkage Analysis}

Linkage analysis is based on study of family(ies) allowing to evaluate the co-segregation of a genetic variant with disease. If a tested marker is close to a disease-causing 
variant the frequency of recombination between them may be sufficiently low to cause a preferential inheritance of the marker among affected individuals, even though the marker itself is not involved in disease pathogenesis. The likelihood of linkage between a disease and genetic marker is described by the odds calculated as the ratio of the likelihood of a given distribution of genotypes in a family assuming linkage vs. assuming random segregation. This likelihood ratio is typically presented as a logarithm with the base of 10 and is called LOD (logarithm of odds) score. A significant evidence for linkage occurs when a LOD score is greater than 3.3 and is replicated at least in two separate studies [8]. In a typical approach a set of $\sim 300$ markers is sufficient to cover the whole genome so that a study can be performed. Whereas linkage analysis has proved valuable in analysis of Mendelian traits its use for examining complex disorders like GD is limited by the requirement for multiplex families and by its low power to detect weak effects. Another limitation of linkage analysis is low resolution which makes it usually impossible to separate effects of loci within 2-3 Mb.

\section{Association Analysis}

Association analysis is a more sensitive method to detect weak genetic risk factors than linkage analysis and currently is the predominantly used method. Association analysis is based on comparing the frequency of a variant in patients and in ethnically matched controls. If a statistically significant difference in the frequency of a variant is observed between cases and controls it is concluded that this variant is associated with disease. The strength and direction of an association is expressed as OR (odds ratio) which is a parameter approximately equal to relative risk (RR) if the disease is relatively rare $(<10 \%)$ which generally is the case for GD. For biallelic polymorphisms such as single nucleotide polymorphisms (SNPs) it is common to calculate OR so that it reflects the effect of the variant with lower population frequency (MAF or minor frequency allele). Whereas association studies offer better resolution than linkage analysis $(\sim 0.5 \mathrm{Mb})$ it still should be emphasized that presence of an association does not imply causality and should usually be interpreted only as pointing to direct involvement of some variant(s) in linkage disequilibrium (LD). Indeed, it is common to observe statistically significant associations of a group of markers whose individual effects cannot be separated due to strong (sometimes absolute) LD [9].

Recently, due to advances in high throughput genotyping technologies it has became possible to conduct genome wide association (GWA) studies, i.e. association studies using hundreds of thousands of markers which allow to scan the entire genome and not only candidate loci suggested by prior hypotheses [10]. Implementation of the GWA approach significantly benefitted from information made available through the HapMap project [11]. Within the HapMap 10 million SNP across the entire human genome were typed allowing to dissect patterns of LD and to define haplotype blocks consisting of highly correlated SNPs. Based on this, an informed selection of SNPs to analyze became possible allowing to maximize coverage without unduly increasing costs.
Despite their unquestionable value GWA studies have limitations such as a potential for false-positive results which necessitates very large sample sizes, genotyping errors or insensitivity to structural variants [12]. Another criticism of current GWA studies stems from the increasingly recognized possibility that in addition to common polymorphisms, which are currently focused on, the disease risk may be significantly influenced by rare $(<0.05)$ or very rare genetic variants $(<0.001)$. For example, recently Surolia et al. [13] identified a number of rare/very rare defective variants within sialic acid acetylesterase (SIAE) gene which together were clearly more prevalent among patients with autoimmune disorders than among controls. Although our data do not support the role of SIAE in GD [14] this study [13] is a good example of an increasingly popular approach in the field of genetics of complex diseases.

\section{Future Approaches - Next Generation Sequencing}

Whereas at present the most interesting novel data on genetics of autoimmune diseases come from carefully designed GWA studies (such a study in GD, not limited to coding variants, is still conspicuously missing!) in the near future this technology may be replaced by even more powerful approaches based on next generation DNA sequencing. Progress in this field makes it possible to sequence genomes or large parts thereof (such as an exome, i.e. all exons from a genome) at unprecedented speed and a wealth of information on rare variants obtained using this technology has already been provided by The 1000 Genomes Project [15]. Whereas at present this effort concentrates on healthy people [15] in the near future similar projects involving patients in addition to controls will most likely be undertaken.

A more detailed discussion of methodological approaches for analysis of genetic predisposition to GD can be found in an excellent recent review [16].

\section{GENES PREDISPOSING TO GD}

\section{HLA Region}

A set of genes located on the short arm of chromosome 6 termed the Major Histocompatibility Complex (MHC) has been attracting attention of immunogeneticists ever since it was shown to determine survival of allogeneic grafts. Human MHC is often referred to as the HLA region in parallel with the major loci which are located there and which encode proteins known as Human Leukocyte Antigens. HLA molecules are central for the function of the immune system because they bind fragments of antigens in the form of peptides and present them to T lymphocytes.

HLA molecules are divided into HLA class I (HLA-A, B, C) and class II (HLA-DR, DQ, DP). HLA class I molecules interact with CD8 lymphocytes which fulfill mainly cytotoxic effector functions. Because all tissues need to be surveyed by CD8 lymphocytes, HLA class I molecules are widely expressed. HLA class II molecules present antigens to CD4 lymphocytes which initiate and regulate specific immune response. Although the final outcome of an encounter with an antigen is determined by many factors, binding of an antigen fragment by HLA class II is necessary 
for the development of any specific immune response. HLA class II molecules are permanently expressed on the surface of cells involved in antigen presentation (dendritic cells, macrophages, B cells) whereas expression in other cells may be induced by inflammation. Apart from their direct involvement in immunologic reactions HLA molecules are necessary for ontogenesis of the immune system since they participate in the maturation and selection of lymphocytes in the thymus [17].

HLA genes and molecules display a polymorphism which is particularly extensive in regions, known as 'pockets', which directly bind peptide residues. HLA polymorphism has profound functional significance because different HLA variants bind a distinct repertoire of peptides. HLA polymorphism results from evolutionary selection driven by advantages associated with a diversification of the pool of variants present in a population. One significant advantage of HLA diversity may be to hinder the spreading of infections.

HLA class I molecules consist of a heavy chain noncovalently bound with beta 2 microglobulin (b2m, also called the light chain) which is non polymorphic and is encoded outside the HLA complex. HLA class II molecules are composed of two chains of similar mass (alpha and beta chain) which are encoded by distinct loci. In case of HLADQ both chains (encoded by the $D Q A 1$ or $D Q B 1$ loci, respectively) are polymorphic whereas in the case of DR and DP significant polymorphism is limited to the beta chain (encoded by the DRB1 or DPB1 loci). Thus, to characterize HLA-DQ, both chains or the appropriate genes need to be analyzed, whereas in the case of DR and DP it is sufficient to analyze the beta chain.

The HLA complex is characterized by strong LD. In Caucasians exceptionally strong LD is found between genes encoding DR and DQ molecules so that presence of a given $D R B 1$ variant to a large extent determines $D Q A 1$ and $D Q B 1$ alleles and the other way around. Because of this strong LD it is often convenient to refer to HLA haplotypes in order to describe blocks of alleles virtually always found together in a population. It is usually difficult to characterize effects of individual alleles forming a haplotype.

Within the MHC complex the problem of LD is relevant also because in the close proximity of HLA genes there are numerous other loci making MHC the most gene rich region in the whole human genome [18]. Some of these loci encode proteins with accessory functions in antigen presentation such as LMP2/LMP7 and TAP1/TAP2 which function in HLA class I pathway, or DMA and DMB which are similarly involved in the HLA class II pathway [19]. Another group of MHC located loci such as TNF, genes encoding complement components or heat shock proteins take part in an immune response without direct interaction with HLA. However, despite clear enrichment for genes involved in immune response, approximately $60 \%$ out of 252 expressed MHC loci have other functions [20].

The majority of autoimmune diseases including GD display strong associations with HLA variants [21]. In Caucasian GD patients increased prevalence of the $D R B 1^{*} 03$ $D Q A 1^{*} 05 \quad D Q B 1^{*} 02$ haplotype is usually observed suggesting that some gene(s) encoded there increase the risk of disease development 2-3 times [22]. At present it is not clear which locus is responsible for the observed association. Out of the three most frequently studied genes encoded on this haplotype $D Q B 1^{*} 02$ can be excluded as it is commonly found on haplotypes encoding $D R B 1^{*} 07$ which appear to protect from GD [23-25]. Conversely, the relative importance of $D Q A 1^{*} 05$ and/or $D R B 1^{* 03}$ is under discussion. Although in some studies a stronger association with $D Q A 1^{*} 05$ was found $[26,27]$ an argument against a primary role of this allele is the lack of established association between GD and $D R B 1^{*} 11 / 12$ which in Caucasians are also in strong LD with $D Q A 1 * 05$.

In contrast to the attempts to disentangle LD by statistical methods, an approach similar to the one originally used to develop 'shared epitope' hypothesis in rheumatoid arthritis [28] suggested a primary role of the DRB1 locus in GD [29]. This suggestion was based on direct analysis of DNA sequence of exon 2 of the HLA-DRB1 gene in 208 GD patients and 149 controls with a focus on amino acid position 74 which was identified as the only polymorphic position among those forming the DR peptide-binding pockets specific for DRB1*03. Whereas variants with arginine at position 74 were expected to be overrepresented among GD patients due to increased prevalence of $D R B I^{*} 03$, the interesting observation was that they were associated with disease also when only $D R B 1 * 03$ negative subjects were considered $(\mathrm{OR}=10.5, \mathrm{P}=0.02)$ [29]. The possibility that DRB1 position 74 is a primary determinant of GD susceptibility was consistent with results of a subsequent study analyzing $D R B 1, D Q B 1$ and $D Q A 1$ loci in 871 patients and 621 controls, although a conclusive test was not possible because of the small number of subjects in whom Arg-74 was not associated with $D R B 1^{*} 03$ [24]. Arg-74 was also found to significantly contribute to the pocket structure conferring risk for HT [30] and was associated with cooccurrence of T1DM with AITD [31].

In parallel with susceptibility conferred by Arg-74 it was proposed that Gln-74 protects against GD [29]. This was consistent with the observation that $D R B 1^{*} 07$ alleles which always encode Gln-74 are found at decreased frequency among GD vs. controls [24,25,29]. Different effects of Gln74 and Arg-74 on HLA-DR peptide binding were also suggested after structural modeling [31].

A turn in the discussion about the role of HLA in GD was brought about by the suggestion that the disease may be primarily associated with alleles of HLA class I, in particular HLA- $C^{*} 07$ [32]. While studying distribution of alleles of the HLA- $B, C, D R B 1, D Q A 1$ and $D Q B 1$ loci among $~ 500$ patients and controls from the UK it was observed that the strongest association was with $\mathrm{HLA}^{*} C\left(\mathrm{P}=1.20 \times 10^{-22}\right)$. Whilst the DRBI was the next most strongly associated locus, the statistical significance of its effect was distinctly lower $\left(\mathrm{P}=6.67 \times 10^{-12}\right)$ [32]. Analysis of individual HLA-C alleles showed that $C^{*} 07$ was the most predisposing allele (OR 1.63) whereas $C^{*} 03$ and $C^{*} 16$ had protective effects. Although the association with HLA-C alleles was the strongest other locus/loci had independent effect(s). When genotypes or alleles of other tested loci were added to a model already containing HLA* $C$ variants, an improvement 
of disease prediction was observed in all analyses with the most pronounced effect for HLA*B. Analyses of individual contribution of $\mathrm{HLA}^{*} B$ alleles showed the strongest effect for $B^{*} 08$ and a protective association for $B^{*} 44$ [32]. Both $C^{*} 07$ and $B^{*} 08$ are encoded on the common haplotype associated with GD in Caucasians which also includes $D R B 1^{*} 03, D Q A 1^{*} 05$ and $D Q B 1^{*} 02$. However, the authors concluded that the observed associations to HLA class I alleles could not be attributed to LD within this haplotype [32].

Whereas Simmonds et al. clearly demonstrated that in Caucasians in addition to $D Q A 1 * 05$ and/or $D R B 1 * 03$ there are other HLA linked genes which are associated with GD a limitation of their study was the lack of analysis of HLA- $A$ and HLA-DPB1 loci [32]. Since in Caucasians the search for association between GD and DPBI alleles has been relatively limited and inconclusive [33-35], it should be interesting to include this locus in adequately powered future studies.

The association between GD and HLA loci from the haplotype encoding $D R B 1^{*} 03 \quad D Q A 1^{*} 05$ and $D Q B 1^{*} 02$, although well documented in Caucasians, is conspicuously absent in other ethnic groups.

The most comprehensive study on HLA associations in GD in an Asian population was recently published by Chen et al. [36]. While studying 500 GD patients and controls selected in a case control design as well as a cohort of families including $>400$ patients these authors found that HLA-DPB ${ }^{*}$ 05:01 was the major gene predisposing to GD among Han Chinese with an $\mathrm{OR}=2.3$ and a high populationattributable risk of $48 \%$. Other susceptibility variants with independent effects included $B^{*} 46: 01, D R B 1^{*} 15: 02$ and 16:02 whereas $D R B 1^{*} 12: 02$ and $D Q B 1^{*} 03: 02$ conferred protection [36]. Unfortunately, the authors did not study the $D Q A 1$ locus so that an effect of $D Q A 1^{*} 05: 01$ whose primary role was postulated in Caucasians [22] was not directly evaluated. However, the authors argued that association of $D Q A 1^{*} 05: 01$ with GD in their cohort was not supported by LD patterns observed in Asians [36]. The data from the study of Chen et al. did not support the role of Arg-74 as proposed in Caucasians [29].

In addition to the novel observations Chen et al. provided an excellent review of previous studies on HLA associations in GD performed among Asian subjects [36]. One interesting conclusion from this review was that the association with $D P B 1^{*}$ 05:01 had been observed in three out of four former studies which analyzed this locus but had not been appropriately focused on subsequently [36].

Relatively few studies on HLA associations with GD have been performed among Blacks [37-42]. Whereas all these studies were based on limited numbers of patients $(\mathrm{n} \sim 50)$ it is noteworthy that only one reported an association with the $D R B 1^{*} 03$ variant [38]. Notably, none of the studies analyzed the $D P B 1$ locus. Since Blacks display the largest HLA diversity, well powered studies of GD in this population may be particularly worth performing in the future.

It is likely that HLA associations with autoimmune diseases including GD are caused by the physiological function of these molecules, i.e. antigen presentation [21]. The frequently postulated hypothesis posits that diseaseassociated variants but not other variants efficiently bind peptides derived from autoantigen(s) such as thyroglobulin or TSHR and thus have a permissive role in the development of immune response. Another possibility is that diseaseassociated HLA variants operate at the stage of thymic selection unfavorably influencing positive and/or negative selection of $\mathrm{T}$ cell clones with regulatory or effector functions. Additional mechanisms proposed to explain HLA class I association included influence on NK (natural killer) cell repertoire through interactions with killer immunoglobulin-like receptors (KIR) and/or serving directly as a source of autoantigens after misfolding and presentation by HLA class II molecules [32]. It should be emphasized that these mechanisms remain speculative.

In conclusion, although the HLA region clearly contains genes predisposing to GD, the exact identity of involved variants or even loci remains unknown. There is an agreement that in Caucasians at least some of these genes are located on common $D R B 1^{*} 03$ haplotypes whereas in Asians an emerging consensus points to a role of the $D P B 1$ variants. It should be emphasized that HLA associated risk for GD may well reflect superimposing effects (also protection) of many alleles of different loci including loci encoding other molecules than HLA. Importantly, the variants involved need not be the same in all ethnic groups due to differences in genetic profile of the background population and/or differences in pathogenesis caused for example by different pathogen milieu.

Clearly high resolution HLA studies across various ethnic groups are needed. Such studies are particularly warranted since the available evidence indicates that similarly as in other autoimmune diseases the HLA linked gene(s) may be the strongest of all genetic factors predisposing to GD.

\section{Protein Tyrosine Phosphatase-22 (PTPN22)}

Lymphoid tyrosine phosphatase (LYP) encoded by the protein tyrosine phosphatase-22 (PTPN22) gene was originally associated with T1DM based on candidate gene approach [43] and subsequently shown to increase the risk for a number of autoimmune diseases including GD [44], rheumatoid arthritis (RA), juvenile idiopathic arthritis (JIA) and autoimmune Addison disease (AAD) [45]. In many autoimmune diseases PTPN22 represents the second most strongly associated locus after HLA.

PTPN22 is involved in limiting the adaptive response to antigen by dephosphorylating and inactivating $\mathrm{T}$ cell receptor (TCR) associated kinases and their substrates. In lymphocytes, PTPN22 physically associates through a proline-rich motif with the SH3 domain of the Csk kinase, an important suppressor of the Src family kinases that mediate TCR signaling. PTPN22 inhibits activation of T cells in a synergistic manner with Csk $[46,47]$.

The best documented association of PTPN22 variants to autoimmune disorders including GD is rs2476601 (C1858T). The disease-associated C1858T SNP, encoding an Arg to Trp substitution at residue 620 (R620W), is located in the P1 
proline-rich motif of PTPN22, which binds with high affinity to the Src homology 3 (SH3) domain of the tyrosine kinase, Csk. The W620 variant disrupts the interaction between PTPN22 and Csk [48] and also increases phosphatase activity, which in turn suppresses TCR signaling more efficiently than the wild-type protein $[49,50]$. In vitro experiments have shown that T-cells expressing the W620 allele may be hyperresponsive, and therefore carriers of this allele may be prone to autoimmunity $[43,48]$. A role of PTPN22 in T-cell regulation has been confirmed by the results of knocking out the murine homologue of PTPN22, which lowered thresholds for T-cell-receptor signaling and inhibited production of IL-2 in these animals [51]. However, in another study, significantly higher numbers of IL-2 producing cells in W620 carriers after autoantigen stimulation have been found, suggesting that the W620 variant is rather a loss-of-function variant [52]. One explanation of these discrepant results is that the decreased levels of IL-2 associated with the W620 variant may be caused, rather than by an increase in activity, by an alteration in the cellular location of PTPN22 which impairs the binding of PTPN22 to the protein tyrosine kinase Csk leading to a phenotypic change [52,53].

Despite these contradictory observations, the net result of the PTPN22 620W substitution appears to be a gain of function with respect to reduction of phosphorylation of key signalling molecules and associated downregulation of TCR signaling which leads to inhibition of expansion of T cells, weakening of the positive selection in the thymus, and reduction of antibodies' production through lowering activity of helper T lymphocytes [51].

Interestingly, there are reports indicating that human PTPN22 also inhibits the activity of B-cell antigen receptor $[50,54]$. Although it seems counterintuitive that the blunted cell activation should lead to increased risk of autoimmunity, there is evidence for such a mechanism also in other models [55]. While a full explanation of these findings is not yet possible, the dysfunction of regulatory cells and deregulation of lymphocyte maturation in the thymus have been invoked as mechanisms [56].

Association between PTPN22 620W polymorphism and GD has been demonstrated in numerous studies among Caucasians with strength typically estimated as OR 1.5-1.9 [44,57-59], which makes this variant one of the strongest known genetic factors predisposing to autoimmune diseases. A gene dose-dependent effect of PTPN22 ' $\mathrm{T}$ ' allele on the age of onset of Graves' disease has been observed in a Polish population [57] but was not replicated in a cohort from the UK [60].

PTPN22 has multiple listed copy number variants (CNVs) encompassing the entire gene. When CNVs deposited in a Database of Genome Variants [61] for the PTPN22 gene were tested, only two controls showed a copy number change, one deletion and one duplication, suggesting that CNVs at this locus do not contribute to the etiology of GD [62].

Although most of the studies focused on the C1858T variant, other polymorphisms of the PTPN22 gene may also be relevant. The variant R263Q has been shown to reduce the risk of systemic lupus erythematosus (SLE) due to reduced phosphatase activity [63]. In a study of patients with GD from the UK population, a haplotype reducing the risk of disease, regardless of the effect of the polymorphism at position 1858, has been identified [64]. The conclusions from this study were generally similar to an earlier one conducted among patients with RA [65]. However, it must be stressed that the protective haplotypes identified in the aforementioned studies were different $[64,65]$. The role of other variants of PTPN22 is particularly interesting in populations of Asians and Africans, in which R620W occurs very rarely or not at all $[66,67]$. The total absence of R620W in patients with AITD was confirmed in the Japanese [68]. However, a subsequent analysis of SNP markers within the region of the PTPN22 gene revealed the presence of a protective haplotype which is different from those identified previously [69].

Overall, available results indicate that apart from the well-known polymorphism C1858T, the PTPN22 locus contains other functionally important variants, particularly those conferring protection. Currently, the identity of these variants, except for R236Q, remains unknown, and their effect can be estimated only indirectly through analysis of haplotypes which differ in frequency between patients and healthy controls.

\section{Cluster of Differentiation 40 (CD40)}

CD40 has been associated with GD as a positional candidate on the basis of a genome-wide linkage study in GD which implicated 20q11 chromosomal region, designated GD-2, as harboring a susceptibility locus [70,71]. A potentially functional SNP in the CD40 gene is the C/T polymorphism (rs1883832) located at position -1 relative to translation start and affecting Kozak sequence which plays a major role in the initiation of the translation. The $\mathrm{C}$ allele of rs 1883832 has been found to confer $\mathrm{OR}=1.6$ for GD among Caucasians whereas the results from in vitro transcription/translation system suggested that this allele predisposed to disease by increasing the efficiency of translation of CD40 mRNA [70,71].

The association between GD and rs1883832 was not replicated in two large case-control studies in the United Kingdom [72,73]. Despite this controversy [72,73] association between the rs1883832 CC genotype and GD has been confirmed in a meta-analysis including 1961 and 1960 Caucasian patients and controls, respectively, as well as 132 patients and 164 controls from Korea $(\mathrm{OR}=1.22,95 \% \mathrm{CI}$ : 1.08-1.38) [74]. The association between GD and $\mathrm{C}$ variant rs1883832 is also supported by studies in the population of Japan although in this population the effect may be limited to patients with late onset of disease [75] and/or to the CC and CT genotypes, suggesting a dominant rather than a recessive model of inheritance $[75,76]$.

Even though a CNV in the CD40 gene is listed in the DGV, Huber et al. while using two different assays failed to find any deletions or duplications of CD40 locus in either the controls or GD patients [62].

CD40 is a surface molecule of the TNFR (tumor necrosis factor receptor) family constitutively expressed on a variety 
of cells in the immune system, including antigen-presenting cells (APCs) and B cells [77], as well as on other types of cells, for example, thyroid follicular cells [78] and orbital fibroblasts [79]. CD40 plays a fundamental role in B cell activation as its ligation provides the necessary costimulatory signal for B cell proliferation, immunoglobulin class switching, antibody secretion, prevention of apoptosis of germinal-center B cells, affinity maturation and generation of long-lived memory cells [80,81]. The physiological ligand for CD40 is the CD154 (CD40L) molecule which is expressed on the surface of activated $\mathrm{T}$ helper cells [82].

Recently, inhibition of CD40 expression by siRNA was evaluated for potential to prevent disease development in mice immunized with adenovirus expressing human TSHR A subunit. However, despite successful lowering of CD40 expression, no effect on the rate of disease induction was observed [83].

\section{The Cytotoxic T Lymphocyte-Associated Factor 4 (CTLA4 also known as CD152)}

CTLA4 consists of four exons encoding different functional domains such as a leader sequence and extracellular, transmembrane as well as cytoplasmic domains. The CTLA-4 protein acts as a potent negative regulator of T-cell response [84,85] and variants of CTLA4 have been consistently associated with numerous autoimmune disorders [86].

CTLA-4 acts by delivering an inhibitory signal through its cytoplasmatic domain which can reverse the classic TCRinduced stop signal needed for physical interaction between $\mathrm{T}$ cell and APC, thus reducing adhesion periods between these cells which in turn decreases cytokine production and proliferation [87-89]. In addition to this cell intrinsic action another model emphasizing the role of soluble CTLA-4 (sCTLA-4) has been proposed [90]. The mechanism of the cell extrinsic action could involve stimulation of regulatory $\mathrm{T}$ cells but the precise mechanism is not clear since elevated levels of sCTLA-4 are found in patients with autoimmunity $[91,92]$. Recently Omaer et al. demonstrated yet another cell extrinsic mode of CTLA-4 action occurring through removal of co-stimulatory ligands (CD86) from APCs via transendocytosis [93]. Clearly, more work is needed to decipher all physiologically relevant effects CTLA4.

The most consistent associations with GD within CTLA4 locus were found with three polymorphisms, the first being the AT-microsatellite polymorphism (ATn) at the 3'untranslated region (3'UTR) of the gene [94,95]. It has been proposed that long AT-repeat allele decreased stability of CTLA4 mRNA thus blunting the inhibitory function of the protein and thus reducing control of T-cell proliferation [96].

The second polymorphism implicated as causative was rs231775, a SNP (A49G ) in the signal peptide causing a substitution Thr to Ala [95,97-103]. This amino acid change could influence post-translational processing leading to inefficient glycosylation of the autoimmunity predisposing variant [104]. However studies conducted by $\mathrm{Hu}$ et al. did not support these observations as both the extrinsic and intrinsic actions of recombinant human CTLA-4 expressed in transfected Jurkat $\mathrm{T}$ cells were not affected by the signal peptide polymorphism indicating that the association of the rs231775 to GD is secondary to LD with the causative variant [105].

Another widely studied genetic CTLA4 polymorphism is rs3087243 located downstream from the 3'UTR of the CTLA4 and also known as CT60 [101,102,106-108]. Investigation of full-length (flCTLA-4) and sCTLA-4 expression after taking into account the CT60 genotype revealed a lower expression of SCTLA-4 in individuals homozygous for the $\mathrm{G}$ allele [109,110]. However, this result was not replicated in a larger Swedish study which also did not find any correlation between concentration of serum sCTLA4 and disease status or CT60 genotype [111]. Recently, a significant association with CTLA4 CT60 was found for GD $(\mathrm{OR}=2.97)$ in Japanese patients. Stratification analyses suggested a possible synergistic interaction of CTLA4 with HLA- $A^{*} 02$ and $-D P B 1^{* 05} 01$ in the susceptibility to GD [112].

In a comprehensive meta-analysis by Kavvoura et al. [113] the A49G and CT60 polymorphisms among Asians and Caucasians have been studied. There were 28 studies that reported data for the A49G polymorphism and 7 for CT60 with a total of 4848 GD cases typed for A49G and 3047 for CT60 as well as 7314 and 3741 healthy controls, respectively. The summary OR for A49G was estimated as 1.49 with respect to G-allele carriers with a significant between-study heterogeneity. Interestingly, the magnitude of the overall OR diminished over time, from 1.64 in 1996 to 1.49 found in meta-analysis by Kavvoura et al. in 2007 [113]. The $\mathrm{G}$ allele of CT60 polymorphism increased odds of GD 1.45 fold and similarly to A49G, there was a significant heterogeneity among studies [113].

The obtained results were similar for Asians and Caucasians but the Asian studies were more divergent [113]. Haplotype analysis indicated that GD association with A49G polymorphism is secondary to LD with CT60 rather then an independent effect. A dose-effect association was observed since carriers of two copies of the risk haplotype had significantly higher odds for disease development when compared to single copy carriers (OR 1.97 vs. 1.29) [113].

Kavvoura et al. also analyzed other CTLA4 polymorphisms previously described and found a modest association of the G alleles of JO31 and JO30 with GD. No significant associations were obtained for the (AT)n microsatellite, $\mathrm{C}(-318) \mathrm{T}$ or JO27_1 polymorphism although it should be noted that these polymorphisms were examined in relatively smaller numbers of studies [113].

The current state of knowledge does not indicate clearly the causal mechanism behind the association of CTLA4 with GD. However, CTLA4 polymorphism is among those most consistently associated with thyroid autoimmune diseases in the majority of populations.

\section{The Thyrotropin Receptor (TSHR)}

The thyrotropin receptor (TSHR) is a Gs-protein coupled receptor responding to thyrotropin (thyroid-stimulating hormone, TSH). It is primarily found on the surface of the thyroid epithelial cells [114]. TSH is central to the regulation 
of the thyroid gland. Since anti-TSHR antibodies in serum are the main serological manifestation of GD, TSHR gene was the obvious candidate for genetic studies. TSHR is located on 14q31 [115,116] and consists of 13 exons [117]. Initial studies focused on the three common non synonymous SNPs in the TSHR: D36H and P52T, both located in the extracellular domain of the receptor, and D727E found in the intracellular part of the protein. Despite the positive results of some studies [118-120], subsequent linkage and casecontrol studies have largely shown no association of GD with either of these TSHR SNPs in Caucasians [121-124]. Nevertheless, genome wide linkage analysis subsequently suggested a GD susceptibility locus in chromosomal region $14 q 31$ [125]. This encouraged extending the search for susceptibility loci to non-coding sequences within the TSHR gene. Among the Japanese large scale analyses of SNPs which were prompted by initial associations found by typing of microsatellites [126] showed evidence for three haplotypes within TSHR intron 7 that were strongly associated with GD [127].

The first evidence for association between TSHR and GD in Caucasians has been provided by Dechairo et al. [128]. These authors analyzed LD structure across the entire TSHR gene, identified LD blocks and analyzed SNPs which captured the majority of intra-block haplotype diversity. One haplotype stretching two LD blocks showed association with GD (OR 1.7), with the most strongly associated SNP (rs2268458) located in intron 1 and conferring $\mathrm{OR}=1.31$ [128].

Further refinement of the association between variants in intron 1 of THSR and GD was provided by studies in a UK population by Brand et al. who investigated a combined panel of 98 SNPs, including rs2268458, across an extended $800 \mathrm{~kb}$ region of the TSHR [129]. Among 28 SNPs associated with the disease the strongest signal was at rs179247 (OR=1.53) and rs12101255 (OR=1.55) [129]. The multiple logistic regression suggested these two SNPs in strong LD explained the association signal in the region [129]. Functional analyses suggested that rs179247 and rs12101255 could be associated with reduced expression of full length TSHR mRNA relative to two truncated splice variants which in turn could lead to increase in shedding of a part of the TSHR receptor called the A-subunit [129]. Since the TSHR A-subunit may be a particularly important target for autoantibodies against TSHR $[129,130]$ its excessive production could well have relevance for GD pathogenesis.

The results obtained in the UK population were recently replicated in a Polish and extended British cohorts [131]. It was found that rs179247 and rs12101255 were in strong but incomplete $\mathrm{LD}\left(\mathrm{D}^{\prime}=0.98\right.$ and $\left.\mathrm{r}^{2}=0.50\right)$. Logistic regression indicated that association at rs 179247 may be secondary to rs 12101255 or that rs12101255 is in stronger LD with the etiological variants within the region [131]. Genotypephenotype correlations provided no clear evidence of association between rs12101255 and any specific clinical characteristics of GD [131].

Although the most strongly associated subregion of TSHR gene is different in Caucasians (intron 1) $[128,129,131]$ and Asians (intron 7) [127] there may be some sharing of genetic susceptibility factors between these populations. A marginal $(\mathrm{P}=0.026)$ association to an intron 1 SNP (rs2268474) was observed by Hiratani et al. in a Japanese cohort [127] whereas another SNP in intron 1 rs2239610 - was associated with GD in a study of an ethnically mixed Asian population from Singapore [132]. Notably, rs2239610 is a perfect proxy of rs2268458 which was associated with GD in Caucasians [128,129]. On the other hand rs3783941, a nonsynonymous SNP in the distal part of the gene (exon 9) has been associated with GD in a large GWAS study of nonsynonymous variants, albeit only after the control group was expanded to include a total of 4500 subjects [133]. As this association was not replicated, it could be a false positive, although there remains a possibility that the lack of replication was due to insufficient power [129].

To summarise, whereas it is safe to conclude that the TSHR gene polymorphism is associated with GD, further fine mapping, perhaps using next-generation sequencing, as well as functional studies will be required to determine the exact location of the etiological DNA variants and to determine to what extent TSHR linked susceptibility factors for GD differ between Caucasian and Oriental populations.

\section{Thyroglobulin (Tg)}

Thyroglobulin (Tg) represents one of the major autoantigens for autoimmune thyroid diseases (AITD), including both GD and Hashimoto's thyroiditis (HT). However, in GD the main autoantigen is TSHR and antibodies against TSHR (TRAb) are found almost exclusively in patients with Graves' hyperthyroidism. In contrast to TRAb, autoantibodies against $\mathrm{Tg}(\mathrm{TgAb})$ are not disease specific and they are found in $80-90 \%$ of HT patients, in $50-70 \%$ of GD patients (usually in lower concentration) and in other forms AITD. The induction of experimental autoimmune thyroiditis in mice using $\mathrm{Tg}$ as an antigen provides further evidence of their major role in the pathogenesis of HT (and not GD) in humans.

The TG gene has been mapped to chromosome 8q24, which has been linked to HT, AITD (GD and HT) or thyroid antibody production in independent studies [125,134,135]. Detailed sequence analysis of the entire TG gene revealed several intronic and exonic SNPs. One SNP cluster in strong LD (in exons 10-12) and a SNP in exon 33 have been analyzed in further association studies in different populations. There is some evidence that TG polymorphisms are associated with general susceptibility to AITD and separately to HT [136-141]. In several studies, association of TG polymorphisms with GD as well as with the relapse of Graves' hyperthyroidism after antithyroid treatment was found [142-146]. Unfortunately, these results have to be interpreted with caution because of rather small sizes of studied groups. Moreover, the association of TG SNPs with AITD, GD or HT could not be uniformly replicated [147]. Possibly the observed inconsistencies reflect differences in the autoimmune response to $\mathrm{Tg}$ in various forms of AITD. Therefore, genetic studies so far support the notion that TG may be a susceptibility gene for AITD in general, and not a specific marker for GD or HT.

There are several possible mechanisms by which TG SNP's could influence susceptibility to AITD. Tg is a large 
glycoprotein dimer, each subunit being $\sim 330 \mathrm{kD}$. The extent of iodination, changes within the amino acid sequence and posttranslational modifications of Tg may lead to changes in antigenicity and binding to HLA. Indeed, experiments in human class II MHC-transgenic ('humanized') mice lacking their own class II MHC genes suggest an important role of human DR3 and DQ8 alleles in initiating Tg-induced experimental thyroiditis [148-150]. Especially exon 33 SNP causing a change from a hydrophobic amino acid (Trp) to a positively charged hydrophilic amino acid (Arg) would be expected to change the structure of Tg. This is in agreement with evidence of the interaction between exon $33 \mathrm{TG}$ variants and HLA-DRB1*03 (Arg74) which increases OR for GD up to $16.1[137,151]$. These results imply that a genegene interaction between an immunoregulatory gene (HLADR) and a thyroid-specific autoantigen gene (TG) may play a role in susceptibility to AITD.

Most recently, a newly identified TG promoter SNP $(-1623 \mathrm{~A} / \mathrm{G})$ was associated with AITD [152]. In vitro studies suggest that the disease-associated $\mathrm{G}$ allele confers increased promoter activity through the binding of the interferon regulatory factor-1 (IRF-1), a major interferon-induced transcription factor. These data fit with observations that interferon- $\alpha$ treatment of chronic hepatitis $\mathrm{C}$ infection may be a trigger of AITD and provide a new mechanism of geneenvironment interaction in inducing thyroid autoimmunity [152]. Finally, an interesting hypothesis which has not been studied posits that differences in transcription of TG in the thymus could influence the negative selection of autoreactive T-lymphocytes.

\section{FCRL3 (FC Receptor-Like-3)}

$F C R L 3$ is a receptor of unknown function with structural homology to classical receptors for immunoglobulin constant chains ( $\mathrm{Fc}$ receptors). The allele $\mathrm{C}$ of rs7528684 located at position -169 in promoter of FCRL3 (FC receptor-like-3) gene was convincingly associated with $\mathrm{GD}(\mathrm{OR}=2.15, \mathrm{P}=$ $0.00000085)$ in a Japanese population [153]. FCRL3 is expressed in lymphoid organs, particular strongly on the surface of the B-cells [153]. Presence of FCRL3 was also demonstrated on the surface of a subset of $\mathrm{T}_{\text {reg }}$ cells characterized by lower relative response to antigenic stimulation and reduced suppressor activity [154]. In the original report, rs7528684 was suggested to have functional significance as the disease-associated $\mathrm{C}$ allele increased affinity for NFKB transcription factor and showed enhanced transcription rate in luciferase assay [153].

The association between GD and FCRL3 was replicated in two studies in a UK population. Simmonds et al. studied 1056 GD patients and 864 controls and reported a difference in allele distribution with statistical significance of $\mathrm{P}=0.024$ [155] whereas The Wellcome Trust Case Control Consortium in an analysis including $2500 \mathrm{GD}$ cases and 2500 controls found an association at rs3761959 (a perfect proxy of rs7528684 according to HapMap) which was significant at $\mathrm{P}=0.0094$ [133]. Notably, in this study, a stronger association $\left(\mathrm{P}=1.6 \times 10^{-5}\right)$ was found with another SNP (rs11264798, located in the intron 8 of FCRL3) [133]. Yet another study in a UK population based on 625 cases and 490 controls failed to observe an association at rs7528684 providing instead some evidence for association at rs2282284 in exon $14(\mathrm{P}=0.02$ before correction for number of comparisons) [156].

In contrast, negative conclusions regarding association of rs7528684 as well as three other SNPs in FCRL3 with GD were reached by $\mathrm{Gu}$ et al. who studied 436 cases and 316 controls from a Chinese population. In the case of rs7528684 the conclusion was particularly strong since an opposite effect (protection) was reported. Unfortunately, interpretation of these data is complicated since for rs7528684 the authors present distribution of $\mathrm{A} / \mathrm{G}$ rather than $\mathrm{C} / \mathrm{T}$ alleles presumably reflecting a nomenclature based on the other DNA strand than in the original study [153]. However, assuming that $A$ corresponds to $T$ and $G$ to $C$ the data presented by $\mathrm{Gu}$ et al. are at odds with their conclusion being instead consistent with increased prevalence of $\mathrm{CC}$ and CT genotypes among cases vs. controls [145].

Recently, the association to the FCRL3 region was fine mapped in 2504 patients and 2688 controls from the UK [157]. Although the study confirmed association of rs3761959 (tagging rs7528684) with GD, this association turned out to be secondary to the effect of two other SNPs within FCRL3: the previously implicated rs11264798 [133] and rs10489678 [157]. Further analysis suggested that rs11264798 may not be the etiological variant, as the effect of risk G allele of this SNP was haplotype dependent being apparent only when present together with the rs10489678 C allele.

Overall the available data suggest that genetic polymorphism(s) modifying susceptibility for GD do exist in the FCRL3 region but the primarily associated variant(s) remain(s) to be found [157].

\section{Secretoglobin 3A2 (SCGB3A2) Gene Encoding Secretory Uteroglobin-Related Protein 1 (UGRP1)}

Variants in the promoter of the $S C G B 3 A 2$ gene encoding secretory uteroglobin-related protein 1 (UGRP1) have been associated with GD in an extensive study of a total of $\sim 2500$ patients and controls from the Chinese population by Song et al. [158] who aimed to explain signals in the chromosomal region $5 \mathrm{q} 12-\mathrm{q} 33$ obtained in previous studies using linkage analysis $[134,159]$. The strongest association reported by Song et al. was to $\mathrm{rs} 1368408 \quad(-112 \mathrm{G} / \mathrm{A}, \mathrm{OR}=1.28$, $\left.\mathrm{P}=1.43 \times 10^{-6}\right)$ and SNP75 (-623 -622 AG/-T, OR=1.32, $\left.\mathrm{P}=7.62 \times 10^{-5}\right)[158]$. Association between GD and the $\mathrm{A}$ allele of $\mathrm{rs} 1368408(\mathrm{OR}=1.18, \mathrm{P}=0.007)$ was independently confirmed in a similarly sized UK cohort (SNP75 was found to have low polymorphism and was not analyzed) [160]. Recently, further evidence for association between rs1368408 and GD was provided by a study in a Russian cohort $\left(\sim 1500\right.$ cases and controls, $\left.\mathrm{OR}=1.33, \mathrm{P}=2.9 \times 10^{-5}\right)$ [161]. It should be noted that a relatively early study in a Chinese population did not observe the effect of rs 1368408 although this might have been caused by low power due to limited numbers of subjects ( $\sim 200$ cases and controls) [162].

The $-112 \mathrm{G} / \mathrm{A}$ variant of SCGB3A2 (rs1368408) was originally discovered by Nimi et al. who also showed that it was functional with the A allele conferring a $24 \%$ reduction of promoter activity [163]. This was confirmed and extended 
by Song et al. who showed that lower expression from haplotypes encoding rs1368408 A was associated with lower concentration of $S C G B 3 A 2$ mRNA also in thyroid tissue [158]. Further support for functional significance of the rs1368408 A variant comes from its association with reduced concentration of UGRP1 in serum of healthy subjects as well as of patients with GD or asthma [161,164]. The functional effect of the A allele of rs1368408 may occur through disruption of the binding site for CCAAT/enhancer-binding protein $\alpha(\mathrm{C} / \mathrm{EBP} \alpha)$ which positively regulates transcription of $S C G B 3 A 2[158,165]$.

UGRP1 is a ligand for macrophage scavenger receptor with collagenous structure (MARCO) [166] which has an important function in the innate immune system of the lung where it binds inhaled particles including microbial pathogens and facilitates their clearance by the macrophage system [167-169]. Accordingly, UGRP1 is predominantly expressed in the lung although a low level expression was also found in human thyroid and kidney $[158,163]$.

At present it is not clear how variants in SCGB3A2 predispose to GD. Whereas expression of this gene in the thyroid does not preclude a local effect the well documented function of MARCO (and presumably UGRP1) in lung physiology suggest that the association may be caused by systemic effects originating from the respiratory system. Interestingly, rs1368408 A has been associated with asthma [163]. Although this was not confirmed, an intriguing link between this variant and total $\mathrm{IgE}$, although limited to healthy controls, was recently suggested [161].

Finally it should be noted that other functionally attractive candidates for association with GD such as cytokine genes: IL3,IL4, IL5, IL9, IL13 and the ADRB2 gene encoding beta-2-Adrenergic receptor are located on chromosome $5 \mathrm{q}$, close to the SCGB3A2 locus. Notably, out of these, variants in IL3 [170,171], IL5 [171] and ADRB2 $[172,173]$ were all associated with GD.

\section{Other Candidate GD Susceptibility Genes}

Because GD is known to share genetic susceptibility with T1DM, a set of SNPs associated with T1DM has been tested in GD (2200 patients, 3600 controls) [174]. Out of 14 SNPs analyzed, seven showed association, although evidence was modest $(0.0018<\mathrm{P}<0.026)$ [174].

The strongest of associations found was to rs17388568 although the direction of effect (protection) was opposite to that found in T1DM [174]. The rs 17388568 is located in chromosome region 4q27 (Tenr-IL2-IL21) containing, among others, the locus for IL2. Given the central role of IL2 in immune response it is perhaps not surprising that this region was also associated with other autoimmune diseases such as celiac disease [175], ulcerative colitis [176], RA [177], JIA [178], psoriasis and psoriatic arthritis [179] and others [180] although in the majority of studies another SNP (rs6822844), only weakly linked with rs17388568, was implicated with the minor allele generally conferring protection [181]. It is indeed possible that the $4 \mathrm{q} 27$ contains more than one susceptibility locus since rs6822844 but not rs 17388568 is associated with RA [181]. In the context of these data, a comprehensive analysis of 4q27 SNPs in GD seems warranted.
The second strongest association reported by Todd et al. was with rs1445898 encoding a non-synonymous aa change (Gln75Arg) in calcyphosine-like protein (CAPSL) which possibly has a role related to calcium binding [174]. This finding was not secondary to the effect of an established risk marker of multiple sclerosis (MS) located in the same region (rs6897932 in IL7R) [182-184] as this SNP was not associated with GD [174].

The association between GD and rs1990760 [A946T in IFIH1 -interferon-induced helicase $\mathrm{C}$ domain 1 also known as melanoma differentiation-associated 5 (MDA-5) or Helicard] on chromosome 2q24.3 observed by Todd et al. [174] was actually reported earlier in another British cohort including 602 patients and 446 controls [185]. A subsequent study in a German population (258 patients, 227 controls) did not report statistically significant association between rs1990760 and GD although the expected trend was noted [186]. No association between rs1990760 and GD was found among the Chinese (261 patients, 206 controls) [187] or the Japanese (290 patients and 229 controls) [188].

The association between autoimmunity and rs1990760 was first found in a GWA of nonsynonymous SNPs in T1DM with the minor allele (threonine) conferring protection [189]. The association with T1D was confirmed by a recent meta-analysis (allelic $\mathrm{OR}=1.176$ ) although with evidence for some $(\mathrm{P}=0.023)$ heterogeneity among studies [190]. rs1990760 and/or other SNPs in the region of IFIH1 were also associated with MS [191,192], RA [193] (although there is controversy here) [194], psoriasis [195] and, tentatively, with SLE [196].

Whereas statistical analyses did not prove that IFIH1 was the primary associated locus, support for this hypothesis came from massive resequencing of IFIHI in T1DM patients and controls which revealed four rare variants (rs35667974/Ile923 Val, rs35337543/IVS8+1, rs35744605/ Glu627X, rs35732034/IVS14+1) associated with the disease, independently both from each other and from rs1990760 [197].

IFIH1 is one of a family of intracellular proteins involved in innate immunity through recognition of viral RNA [198]. Interestingly, available data indicate that a normal (i.e. encoded by the more prevalent allele/haplotype) activity of IFIH1 increases the disease risk whereas rare variants confer protection. Whereas the rare variants identified by Nejentsev et al. were associated with a decreased/absent protein activity, the functional consequences of variation are less clear for rs1990760 since the Thr946Ala change did not influence double stranded RNA binding or IFN gene activation [197,199]. It has been shown that Ala946 is associated with reduced IFIHI transcription [200,201] but there are also reports conflicting with this conclusion [194,202].

Association to rs9653442 on $2 q 11$ [174] may indicate the role of locus $A F F 3$ which encodes nuclear protein LAF-4 with homology to a protein involved in leukemia development and a possible function in lymphoid ontogenesis [203]. Through a perfect proxy SNP (rs1160542) rs9653442 has also been associated with RA and JIA $[178,204]$. 
Another novel association in GD suggested by Todd et al. was to rs763361 - a nonsynonymous SNP (Thr307Ser) in the intracellular tail of the CD226 molecule (DNAXaccessory molecule-1 (DNAM-1)) which is a surface receptor with a co-stimulatory function [174]. CD226 is expressed in cells of haematopoetic lineage such as CD4+ and CD8+ T lymphocytes, platelets, as well as some B cells, and natural killer (NK) T lymphocytes [205-207]. Apart from the link with T1D and the tentative association with GD [174] rs763361 has been associated with MS [208], RA [208], SLE [209], Wegener's granulomatosis [210] and systemic sclerosis [211].

The 307Ser variant alters splicing of the CD226 transcript and this has been suggested to explain the association [174]. Another not exclusive possibility is that the amino acid change increases receptor signaling by strengthening the phosphorylation of neighboring sites $[208,209]$. Conversely, recent in vitro analysis indicated a direct functional effect of another SNP closely linked with rs763361 (rs727088), with the disease associated variant causing a decreased expression [208,209]. Consistent with this was the in vivo observation that disease-associated rs763361-rs727088 haplotype correlated with lower surface expression of CD226 in T cells and NKT (Natural Killer T) cells [209]. Since no such genotype-dependent differences in expression were observed in NK or B cells it was suggested that CD226 function in T cells or NKT cells was important in disease pathogenesis [209].

Independent associations with GD were also found with two SNPs (rs1893217 and rs478582) in the region of PTPN2 [174]. PTPN2 was initially associated with T1DM, Crohn's disease and RA in a study by Wellcome Trust Case Control Consortium (WTCC) including $~ 3000$ shared controls and sets of $\sim 2000$ patients with common diseases including the abovementioned autoimmune disease [212]. These results were later extended to ulcerative colitis [213], JIA [214] and possibly celiac disease [215].

Whereas the originally reported association between PTPN2 and autoimmunity was to rs2542151, the SNPs which were tested and found associated with GD (i.e. rs1893217 and rs478582) were those which showed stronger association to T1DM than rs2542151 [174]. Subsequently it was suggested that there was even stronger association with T1DM at rs45450798 so that this marker should replace rs1893217 [215] but so far there have been no data on association with GD of rs1893217 or SNPs in the PTPN2 region other than rs1893217 or rs478582.

$P T P N 2$ encodes a classical, non-receptor protein tyrosine phosphatase, related to but distinct from PTPN22 which is a very well established risk factor for autoimmunity (see above). PTPN2 is highly expressed in hematopoietic cells and the phenotype of the knockout mouse model indicates its important role in immune system development, function and predisposition to autoimmunity [216].

Apart from the loci associated with T1DM [174] and discussed above, a number of other genes such as $V D R$ (vitamin D receptor) [217,218], FOXP3 (a gene whose expression determines $\mathrm{T}_{\text {reg }}$ commitment), DIO2 (type II iodothyronine deiodinase), [119], IL23R (IL23 receptor)
[219] have been associated with GD, based on candidate gene approach (reviewed in [16]).

In addition to the loci discussed above, a recent study from our group suggested that the A allele of rs4986938 within ESR2 (estrogen receptor beta) locus was associated with GD, in particular among $D R B 1^{*} 03$-negative subjects [220]. Subsequently, rs4986938 was associated with SLE [221] and differences of ESR2 mRNA concentration suggesting that increased expression of this gene may predispose to autoimmunity [222].

We also reported an association between NFKB1-94del ATTG (a promoter variant of a gene encoding nuclear factor$\kappa \mathrm{B})$ and GD which was found in two independent Polish cohorts $[\mathrm{P}=0.00005 ; \mathrm{OR}=1.37$ (1.18-1.60)] [223]. Although the association with susceptibility to GD could not be replicated in a Japanese cohort, subgroup analysis in Japanese GD patients revealed a correlation between the $N F K B 1$ genotype and the development of GO as well as the age of disease onset [223]. NFKB1-94del ATTG has been associated with a decreased transcription [224] and its prevalence was assessed in cohorts with various autoimmune diseases although with variable results [225]. These observations, together with the broad role of nuclear factor$\kappa \mathrm{B}$ in immune function [226], make NFKB1-94del ATTG an interesting candidate for further studies in thyroid autoimmunity.

\section{Skewed X Chromosome Inactivation (XCI)}

In female cells, one of the two $\mathrm{X}$ chromosomes is inactivated in early embryonic life and this epigenetic system assures that men and women have equal expression of the genes from the $\mathrm{X}$ chromosome, despite the difference in $\mathrm{X}$ chromosome copy number. The $\mathrm{X}$ chromosome inactivation (XCI) has been regarded a random process which on average leads to inactivation of the maternal and paternal $\mathrm{X}$ chromosomes in $50 \%$ of cells, respectively. However, in accordance with normal distribution, this random process sometimes generates an unbalanced inactivation pattern with one copy of the X chromosome preferentially expressed.

Skewed XCI could also result from a bias in the initial choice of the $\mathrm{X}$ chromosome which is inactivated due to germline XIST (X-inactive-specific transcript) mutations [84] or deleterious X-linked mutations, $X$ chromosome rearrangements, ageing, twinning, or monoclonal expansion of cells [227]. Importantly, the degree of XCI skewing may also be determined by polymorphic variants on the $\mathrm{X}$ chromosome, in particular those located close to the $\mathrm{X}$ inactivation centre or chromosomal bands Xq25-q26 [228231]. Significant skewing of XCI has been arbitrarily defined as a situation in which $80 \%$ or more of the cells inactivate the same X chromosome [232].

The original study linking XCI with GD was based on 32 pairs of female twins with AITD (including 19 with GD) and 96 healthy female twin individuals [233]. The study demonstrated a higher prevalence of skewed XCI in blood cells of females with AITD compared with controls. Moreover, skewed XCI was more frequent in female twins with AITD than in their healthy co twins [233]. 
These results were confirmed by three studies in other populations [234-236]. Ozcelik et al. demonstrated skewed XCI in peripheral blood mononuclear cells in a significant proportion $(34 \%)$ of female subjects with AITDs and $8 \%$ of control females [234]. The effect was even more pronounced when extreme patterns of XCI skewing (90:10 or more) were considered - in such an analysis it was found that $20 \%$ of AITDs patients showed skewing, compared with only a few percent of control subjects. Skewed XCI $(73: 27)$ was also demonstrated in thyroid specimens [234]. Yin et al. in a study based on 87 patients with GD, 47 patients with HT and 69 controls confirmed that XCI skewing was associated with both GD and HT $(\mathrm{OR}=4.0)$ [235]. Similar conclusions were reached by Chabchoub et al. based on a study of 58 GD patients, 87 HT patients and 257 controls [236]

The explanation of the mechanism by which skewed XCI can lead to autoimmunity has been based on the loss of mosaicism hypothesis which posits that lower expression of self-antigens from one $\mathrm{X}$ chromosome may interfere with induction of tolerance in the thymus [237-239]. The inefficient negative selection in the thymus could result from the fact that the cells mediating it (i.e. the thymic epithelial and dendritic cells) are derived from a few progenitors $(\sim 1$ and $\sim 10$, respectively) which makes expression of antigens exclusively from one $\mathrm{X}$ chromosome possible, especially in the presence of skewed XCI [238]. Owing to an overlap between HLA class I and II antigen presentation pathways these untolerized $\mathrm{T}$ cells could in turn provide help to a population of B cells expressing these antigens, thus causing their polyclonal activation. Whereas originally proposed to explain pathogenesis of SLE [238] this mechanism could conceivably decrease the threshold also for other forms of autoimmunity, including GD.

Another mechanism of autoimmunity development could be related to differences in the degree of XCI skewage found among different tissues [232]. In particular, it could happen that antigens with low expression in the thymus are relatively highly expressed in peripheral tissues (such as thyroid) and induce autoimmunity [237-239].

Skewed XCI may offer an interesting explanation for a marked female preponderance of AITD [233]. However, this explanation is difficult to reconcile with the lack of skewed XCI observed in other autoimmune disorders with female preponderance such as MS, SLE or primary biliary cirrhosis [240-242] as well as data from animal experiments showing that female predisposition to autoimmunity is not influenced by homozygosity for $\mathrm{X}$ chromosome which should eliminate defective tolerance induction due to skewed XCI [236,243].

Although the association between skewed XCI and AITD has been found repeatedly [233-236] its mechanism should be regarded as speculative. Recently the same group who described the original association between AITD and skewed XCI provided preliminary evidence of its noncausality [244]. The argument was based on lack of correlation of within-pair differences in values of XCI with differences in concentration of autoantibodies against thyroid peroxidase observed in MZ but not DZ twin pairs [244]. Whereas the study had limited power mainly because of high within-pair similarities in the concentration of autoantibodies among
MZ, its results were interpreted to suggest that skewed XCI and AITD both share genetic determinants but are not causally related [244].

Since the degree of XCI skewing may be linked with markers on the X chromosome [231] such an interpretation would suggest that there are as yet unidentified AITD susceptibility loci located on the $\mathrm{X}$ chromosome. The relevance of the $\mathrm{X}$ chromosome for AITD susceptibility is supported by findings of increased disease risk in Turner's syndrome, in particular among females with isochromosome $\mathrm{Xq}$, i.e. an $\mathrm{X}$ chromosome with deletion of the short arm and duplication of the long arm [245] as well as by observations of increased prevalence of $\mathrm{X}$ chromosome monosomy in $\mathrm{T}$ and B lymphocytes of females with AITD compared with healthy women [246]. The existence of GD susceptibility loci on the $\mathrm{X}$ chromosome was suggested by early studies based on linkage analysis, but without agreement regarding the exact location $[247,248]$. It should be interesting to look for X linked loci when a GWA study is eventually completed in GD.

\section{Fetal Microchimerism (fMC)}

Fetal microchimerism refers to presence within the maternal organism of a small population of cells originating from the fetus. fMC arises during pregnancy and may persist for years or decades [249]. A convenient method to study fMC consists of looking among females for male cells or their DNA [249].

Since the presence of foreign cells can potentially cause immune deregulation it has been hypothesized that $\mathrm{AMC}$ may be a risk factor for AITD and also explain its female predominance as well as frequently observed association between disease onset/aggravation and the postpartum period [250,251]. A first link between fMC and thyroid pathology was provided by demonstration of male cells in thyroidectomy specimens from female patients but not in control autopsy samples [252]. Interestingly, whereas fMC accompanied various thyroid pathologies it was most prevalent in women with HT (5/6 or 83\%) [252]. Association between HT and $\mathrm{FMC}$ was also found by Klintschar et al. who detected fMC in $8 / 17$ patients vs. $1 / 25$ controls [253]. Subsequently, the same group extended these findings using a different methodology [254]. Studying fresh-frozen specimens Ando et al. found high prevalence (6/7) of $\mathrm{fMC}$ in patients with GD vs. controls with thyroid adenoma (1/4) [255]. Somewhat lower prevalence of fMC (4/26 vs. $0 / 6$, respectively) was obtained in the same study from paraffinembedded material which might have suffered from degradation [255]. The association between HT/GD and fMC was also confirmed in a relatively large study of 25 women with HT, 15 with GD and 9 with thyroid adenomas in which prevalence of fMC was $60 \%, 40 \%$ and $22 \%$, respectively for HT, GD and controls [256].

Whereas association between fMC and AITD is well documented, it is not clear whether fMC causes the thyroid disease or vice versa. Some indirect support for a causative role of microchimerism in AITD has been provided by an observation that twins from opposite sex pairs have a higher frequency of thyroid autoantibodies then monozygotic twins [257]. However, in this setting, the relevant microchimersim 
should result from in utero cell trafficking between twins rather than from migration of fetal cells into the mother organism and thus could be qualitatively different [257].

In a murine experimental autoimmune thyroiditis model it was shown that inflamed (but not healthy) thyroid accumulated fetal cells, including $\mathrm{T}$ cells and dendritic cells [258]. Although these cells could theoretically contribute to postpartum exacerbation of thyroid inflammation $[251,258,259]$ these data are compatible with high prevalence of fMC in human AITD being a consequence rather than the cause of disease. Indeed, the hypothesis that presence of fetal cells was associated with the maternal response to injury (inflammatory or other) as opposed to causing disease was proposed relatively early [260] and is consistent with observations in animal models [261-263] and humans [264].

Furthermore, if fMC were a cause of AITD, an epidemiological association between thyroid autoimmunity and history of pregnancy/parity would be expected. Whereas such an association was indeed found in one cohort [265] it was not observed in four other studies [266-269].

Thus, despite association with AITD, fMC is most likely not a risk factor for disease development. Whereas the role of $\mathrm{fMC}$ in postpartum disease aggravation cannot be excluded, available data suggest that this and other sex related features of GD such as female preponderance will perhaps be more readily explained by hormonal differences between females and males. Interestingly, in pathogenesis of AITD a role for hyperestrogenic state due to a longer reproductive span has been proposed [266]. The role of hormonal factors in thyroid autoimmunity is also consistent with the association discussed above between GD and a ESR2 variant [220].

A broader discussion of the role of fMC in autoimmunity and other diseases such as cancer can be found in a recent review [270].

\section{GENOTYPE-PHENOTYPE CORRELATIONS IN GD}

GD is typically characterized by hyperthyroidism, diffuse goiter and the presence of stimulating TSH receptor autoantobodies (TRAb). The severity of thyrotoxicosis in $\mathrm{GD}$ is variable and the response to anti-thyroid drugs is difficult to predict. Graves' ophthalmopathy (GO) is the most common extrathyroidal manifestation of GD. GO significantly impairs the quality of life of affected patients and the most severe cases can be threaten sight. Although the genetic predisposition to GD is well established, the

Table 1. Selected Genetic Markers Associated with Susceptibility to Graves' Ophthalmopathy

\begin{tabular}{|c|c|c|c|c|}
\hline Locus & Polymorphism (allele) & Population [Ref.] & Studied groups & P-value, odds ratio \\
\hline \multicolumn{5}{|c|}{ Immune- modifying genes: cytokines } \\
\hline IFN- $\gamma$ & intron $1(\mathrm{CA})$ repeat & $\begin{array}{l}\text { Canada and German } \\
\text { [276] }\end{array}$ & $\mathrm{GO}(\mathrm{n}=53), \mathrm{GH}(\mathrm{n}=149)$ & $\begin{array}{l}\mathrm{P}<0.00001, \mathrm{OR}=4.8 \\
\text { For allele } \\
\text { IFN-Y*3 }\end{array}$ \\
\hline TNF & C-863A & Japan [277] & $\mathrm{GO}(\mathrm{n}=62), \mathrm{GH}(\mathrm{n}=111)$ & $\mathrm{P}=0.003, \mathrm{OR}=2.7$ \\
\hline $\mathrm{TNF}$ & $\mathrm{T}-1031 \mathrm{C}$ & Japan [277] & $\mathrm{GO}(\mathrm{n}=62), \mathrm{GH}(\mathrm{n}=111)$ & $\mathrm{P}=0.0003, \mathrm{OR}=3.3$ \\
\hline TNF & G-238A & Poland [278] & GO $(n=106), \mathrm{GH}(\mathrm{n}=122)$ & $\mathrm{P}=0.008, \mathrm{OR}=0.1$ \\
\hline IL-23R & rs2201841 & USA [219] & GO (n=103), GH (n=111) & $\mathrm{P}=0.008, \mathrm{OR}=1.8$ \\
\hline IL-1 A & C-889T & Iran [279] & $\mathrm{GO}(\mathrm{n}=50), \mathrm{GH}(\mathrm{n}=57)$ & $\mathrm{P}=0.006, \mathrm{OR}=2.16$ \\
\hline IL-5 & rs2069812 & China [171] & GO $(n=190)$, GH $(n=561)$ & $\mathrm{P}=0.003, \mathrm{OR}=1.45$ \\
\hline IL-16 & rs 4778889, rs 1131445, rs 4778641 & China $[280]$ & GO $(n=136), \mathrm{GH}(\mathrm{n}=122)$ & $\begin{array}{l}\text { Haplotype (C-T-C) } \mathrm{P}=0.013 \text {, } \\
\mathrm{OR}=0.57\end{array}$ \\
\hline \multicolumn{5}{|c|}{ Immune- modifying genes: other } \\
\hline CTLA4 & A49G & UK [281] & GO (n=129), GH (n=172) & $\mathrm{P}=0.006, \mathrm{OR}=2.1$ \\
\hline CTLA4 & C-318T & China [282] & $\mathrm{GO}(\mathrm{n}=142), \mathrm{GH}(\mathrm{n}=121)$ & $\mathrm{P}=0.009, \mathrm{OR}=0.51$ \\
\hline ICAM-1 & A1405G & Poland [283] & $\mathrm{GO}(\mathrm{n}=108), \mathrm{GH}(\mathrm{n}=127)$ & $\mathrm{P}=0.003, \mathrm{OR}=1.8$ \\
\hline PTPN12 & $\begin{array}{l}\text { rs } 1468682, \\
\text { rs } 4729535\end{array}$ & UK [284] & mild GO\# ( $\mathrm{n}=354), \mathrm{GH}(\mathrm{n}=366)$ & $\begin{array}{l}\mathrm{P}=0.004, \mathrm{OR}=1.41 \\
\mathrm{P}=0.006, \mathrm{OR}=1.37\end{array}$ \\
\hline NFKB1 & -94ins/del ATTG & Japan [223] & $\mathrm{GO}(\mathrm{n}=123), \mathrm{GH}(301)$ & $\mathrm{P}=0.009, \mathrm{OR}=1.37$ \\
\hline TLR-9 & rs 352140 & Taiwan [285] & GO (n=200), GH (271) & $\begin{array}{l}\mathrm{P}=0.03, \mathrm{OR}=1,97 \\
\text { in male GD patients }\end{array}$ \\
\hline CD86 & rs_9831894 & Taiwan [286] & GO (n=200), GH (271) & $\mathrm{P}=0.0017$ \\
\hline
\end{tabular}

GO - Graves' ophthalmopathy, GH - Graves' hyperthyroidism without eye disease, HS - healthy subjects.

\#Mild GO - NOSPECS score 2-4. 
Table 2. Selected Genetic Markers Associated with the Clinical Course of Hyperthyroidism in Graves' Disease

\begin{tabular}{|c|c|c|c|c|}
\hline Locus & Polymorphism (allele) & Population & Studied group & Evaluated parameter \\
\hline \multicolumn{5}{|c|}{ Immune- modifying genes } \\
\hline HLA & HLA-DRB1 $* 07$ & Denmark [287] & Juvenile GD (n=102) & \multirow[t]{5}{*}{ Age of onset of GD } \\
\hline ICAM-1 & G721A & Poland [283] & $\mathrm{GD}(\mathrm{n}=235)$ & \\
\hline PTPN22 & $\mathrm{C} 1858 \mathrm{~T}$ & Poland [57] & $\mathrm{GD}(\mathrm{n}=290)$ & \\
\hline NFKB1 & -94ins/del ATTG & Japan [223] & $\mathrm{GD}(\mathrm{n}=424)$ & \\
\hline CD40 & $\mathrm{C}-1 \mathrm{~T}$ & Taiwan[143] & $\mathrm{GD}(\mathrm{n}=215)$ & \\
\hline CTLA4 & $\mathrm{A} 49 \mathrm{G}$ & Japan [288] & $\mathrm{GD}(\mathrm{n}=144)$ & \multirow{5}{*}{$\begin{array}{l}\text { Remission/relapse rate after ATD } \\
\text { treatment }\end{array}$} \\
\hline CTLA4 & $\mathrm{A} 49 \mathrm{G}$ & Japan [289] & $\mathrm{GD}(\mathrm{n}=415)$ & \\
\hline CTLA4 & A49G & Taiwan [290] & $\mathrm{GD}(\mathrm{n}=208)$ & \\
\hline CTLA4 & $\mathrm{A} 49 \mathrm{G}$ & Turkey [146] & GD $(n=97)$ & \\
\hline TG & E33SNP & Taiwan [142] & $\mathrm{GD}(\mathrm{n}=215)$ & \\
\hline CXCL10 & rs 8878 & Germany [291] & $\mathrm{GD}(\mathrm{n}=228)$ & Severe course of GD\# \\
\hline CTLA4 & A49G & Slovenia [292] & GD $(n=67)$ & $\mathrm{TPOAb}$ and $\mathrm{TgAb}$ levels \\
\hline TNF & C-857T & Japan [293] & $\mathrm{GD}(\mathrm{n}=75)$ & TRAb level \\
\hline \multicolumn{5}{|c|}{ Thyroid-specific genes } \\
\hline TSHR & rs2239610 & China [145] & $\mathrm{GD}(\mathrm{n}=436)$ & FT4 and TRAb levels \\
\hline
\end{tabular}

ATD anti-thyroid drugs, TPOAb anti-thyroid peroxidase antibodies, TGAb anti-thyroglobuline antibodies, TRAb anti-TSHR antibodies.

\#The cutoff for a severe course of GD was defined by the presence of Graves' ophthalmopathy, recurrent hyperthyroidism, thyreotoxic crisis, large goiter and/or other autoimmune diseases.

significance of genotype-phenotype correlations remains controversial. Moreover, the lack of complete phenotypic concordance in $\mathrm{MZ}$ pairs strongly indicates that environmental and/endogenous factors are of importance [271]. The major environmental factor influencing the clinical course of GD is cigarette smoking.

Several genes have been shown to confer susceptibility to GO (Table 1). Unfortunately, the results of these studies have to be judged very carefully [272]. It is now apparent that "reliable" association studies should consist of large datasets, small $\mathrm{P}$ values, functional polymorphisms and an independent replication. The vast majority of studies analyzing genetic susceptibility to GO are small and underpowered, resulting in a high risk of both false positive and false negative results. Replication studies are lacking or were unable to confirm the initial association between immunoregulatory genes polymorphisms and GO. Finally, the studied groups were usually poorly characterized and the definition of "clinically evident ophthalmopathy" varied between studies.

Similarly, some studies suggested an association between candidate genes polymorphisms and the course of hyperthyroidism (Table 2): the age of onset of GD, the relapse rates after anti-thyroid drug treatment and/or the level of anti-thyroid antibodies, with the same limitations as above. Most studies suggested an association between CTLA4 SNP (A49G) and severity of Graves' hyperthyroidism. However, these findings could not be uniformly confirmed [273-275].
At present, while some genetic differences between subgroups of GD patients have been identified, none of the polymorphisms justifies genetic testing to guide therapy or preventive strategies. Genotype-phenotype correlations in GD remain to be elucidated in the future, through well designed and appropriately powered studies.

\section{NOTE ADDED IN A PROOF}

While this article was in press a genome-wide association study of GD in a Chinese population was published by $\mathrm{Chu}$ et al. (Nature Genetics 2011; 43: 897). The study confirmed four previously reported loci (HLA, TSHR, CTLA4 and FCRL3) and identified two new susceptibility markers (rs9355610 and rs6832151).

\section{ACKNOWLEDGEMENT}

Supported by Warsaw Medical University grants $1 \mathrm{WY} / \mathrm{N} / 11$ and $1 \mathrm{WN} / \mathrm{NK} 1 \mathrm{~W}$.

\section{REFERENCES}

[1] Hall, R.; Stanbury, J.B. Familial studies of autoimmune thyroiditis. Clin. Exp. Immunol., 1967, 2, Suppl-25.

[2] Villanueva, R.; Inzerillo, A.M.; Tomer, Y.; Barbesino, G.; Meltzer, M.; Concepcion, E.S.; Greenberg, D.A.; MacLaren, N.; Sun, Z.S.; Zhang, D.M.; Tucci, S.; Davies, T.F. Limited genetic susceptibility to severe Graves' ophthalmopathy: no role for CTLA-4 but evidence for an environmental etiology. Thyroid, 2000, 10, 791798.

[3] Brix, T.H.; Christensen, K.; Holm, N.V.; Harvald, B.; Hegedus, L. A population-based study of Graves' disease in Danish twins. Clin. Endocrinol.(Oxf), 1998, 48, 397-400. 
[4] Brix, T.H.; Kyvik, K.O.; Christensen, K.; Hegedus, L. Evidence for a major role of heredity in Graves' disease: a population-based study of two Danish twin cohorts. J. Clin. Endocrinol. Metab., 2001, 86, 930-934.

[5] Ringold, D.A.; Nicoloff, J.T.; Kesler, M.; Davis, H.; Hamilton, A.; Mack, T. Further evidence for a strong genetic influence on the development of autoimmune thyroid disease: the California twin study. Thyroid, 2002, 12, 647-653.

[6] Stenszky, V.; Kozma, L.; Balazs, C.; Rochlitz, S.; Bear, J.C.; Farid, N.R. The genetics of Graves' disease: HLA and disease susceptibility. J. Clin. Endocrinol. Metab., 1985, 61, 735-740.

[7] Farid, N.R. Understanding the genetics of autoimmune thyroid disease--still an illusive goal! J. Clin. Endocrinol. Metab., 1992, 74, 495A-495B.

[8] Lander, E.; Kruglyak, L. Genetic dissection of complex traits: guidelines for interpreting and reporting linkage results. Nat. Genet., 1995, 11, 241-247.

[9] Hodge, S.E. What association analysis can and cannot tell us about the genetics of complex disease. Am. J. Med. Genet., 1994, 54, 318-323.

[10] Hirschhorn, J.N.; Daly, M.J. Genome-wide association studies for common diseases and complex traits. Nat. Rev. Genet., 2005, 6, $95-$ 108 .

[11] The International HapMap Project. Nature, 2003, 426, 789-796.

[12] Pearson, T.A.; Manolio, T.A. How to interpret a genome-wide association study. JAMA, 2008, 299, 1335-1344.

[13] Surolia, I.; Pirnie, S.P.; Chellappa, V.; Taylor, K.N.; Cariappa, A.; Moya, J.; Liu, H.; Bell, D.W.; Driscoll, D.R.; Diederichs, S.; Haider, K.; Netravali, I.; Le, S.; Elia, R.; Dow, E.; Lee, A.; Freudenberg, J.; De Jager, P.L.; Chretien, Y.; Varki, A.; MacDonald, M.E.; Gillis, T.; Behrens, T.W.; Bloch, D.; Collier, D.; Korzenik, J.; Podolsky, D.K.; Hafler, D.; Murali, M.; Sands, B.; Stone, J.H.; Gregersen, P.K.; Pillai, S. Functionally defective germline variants of sialic acid acetylesterase in autoimmunity. Nature, 2010, 466, 243-247.

[14] Szymanski, K.; Skorka, A.; Szypowska, A.; Bednarczuk, T.; Ploski, R. Functionally defective germline variant of sialic acid acetylesterase (Met89Val) is not associated with type 1 diabetes mellitus and Graves' disease in a Polish population. Tissue Antigens, 2011.

[15] Durbin, R.M.; Abecasis, G.R.; Altshuler, D.L.; Auton, A.; Brooks, L.D.; Durbin, R.M.; Gibbs, R.A.; Hurles, M.E.; McVean, G.A. A map of human genome variation from population-scale sequencing. Nature, 2010, 467, 1061-1073.

[16] Simmonds, M.J.; Gough, S.C. The search for the genetic contribution to autoimmune thyroid disease: the never ending story? Brief Funct. Genomics, 2011, 10, 77-90.

[17] Kisielow, P.; von Boehmer, H. Development and selection of T cells: facts and puzzles. Adv. Immunol., 1995, 58, 87-209.

[18] Rhodes, D.A.; Trowsdale, J. Genetics and molecular genetics of the MHC. Rev. Immunogenet., 1999, 1, 21-31.

[19] Monaco, J.J. Pathways for the processing and presentation of antigens to T cells. J. Leukoc. Biol., 1995, 57, 543-547.

[20] The MHC sequencing consortium. Complete sequence and gene map of a human major histocompatibility complex. Nature, 1999, 401, 921-923.

[21] Gough, S.C.; Simmonds, M.J. The HLA Region and Autoimmune Disease: Associations and Mechanisms of Action. Curr. Genomics, 2007, 8, 453-465.

[22] Simmonds, M.J.; Gough, S.C. Unravelling the genetic complexity of autoimmune thyroid disease: HLA, CTLA-4 and beyond. Clin. Exp. Immunol., 2004, 136, 1-10

[23] Chen, Q.Y.; Huang, W.; She, J.X.; Baxter, F.; Volpe, R.; Maclaren, N.K. HLA-DRB108, DRB103/DRB30101, and DRB30202 Are Susceptibility Genes for Graves' Disease in North American Caucasians, Whereas DRB107 Is Protective. J. Clin. Endocrinol. Metab., 1999, 84, 3182-3186.

[24] Simmonds, M.J.; Howson, J.M.M.; Heward, J.M.; Cordell, H.J.; Foxall, H.; Carr-Smith, J.; Gibson, S.M.; Walker, N.; Tomer, Y.; Franklyn, J.A.; Todd, J.A.; Gough, S.C.L. Regression mapping of association between the human leukocyte antigen region and graves disease. Am. J. Hum. Genet., 2005, 76, 157-163.

[25] Kula, D.; Bednarczuk, T.; Jurecka-Lubieniecka, B.; Polanska, J.; Hasse-Lazar, K.; Jarzab, M.; Steinhof-Radwanska, K.; Hejduk, B.; Zebracka, J.; Kurylowicz, A.; Bar-Andziak, E.; Stechly, T.; Pawlaczek, A.; Gubala, E.; Krawczyk, A.; Szpak-Ulczok, S.;
Nauman, J.; Jarzab, B. Interaction of HLA-DRB1 alleles with CTLA-4 in the predisposition to Graves' disease: the impact of DRB1*07. Thyroid, 2006, 16, 447-453.

[26] Yanagawa, T.; Mangklabruks, A.; Chang, Y.B.; Okamoto, Y.; Fisfalen, M.E.; Curran, P.G.; DeGroot, L.J. Human histocompatibility leukocyte antigen-DQA $1 * 0501$ allele associated with genetic susceptibility to Graves' disease in a Caucasian population. J. Clin. Endocrinol. Metab., 1993, 76, 1569-1574.

[27] Barlow, A.B.; Wheatcroft, N.; Watson, P.; Weetman, A.P. Association of HLA-DQA1*0501 with Graves' disease in English Caucasian men and women. Clin. Endocrinol. (Oxf), 1996, 44, 7377.

[28] Gregersen, P.K.; Silver, J.; Winchester, R.J. The shared epitope hypothesis. An approach to understanding the molecular genetics of susceptibility to rheumatoid arthritis. Arthritis Rheum., 1987, 30, 1205-1213.

[29] Ban, Y.; Davies, T.F.; Greenberg, D.A.; Concepcion, E.S.; Osman, R.; Oashi, T.; Tomer, Y. Arginine at position 74 of the HLA-DR [beta]1 chain is associated with Graves' disease. Genes Immun., 2004, 5, 203-208.

[30] Menconi, F.; Monti, M.C.; Greenberg, D.A.; Oashi, T.; Osman, R.; Davies, T.F.; Ban, Y.; Jacobson, E.M.; Concepcion, E.S.; Li, C.W.; Tomer, Y. Molecular amino acid signatures in the MHC class II peptide-binding pocket predispose to autoimmune thyroiditis in humans and in mice. PNAS, 2008, 105, 14034-14039.

[31] Menconi, F.; Osman, R.; Monti, M.C.; Greenberg, D.A.; Concepcion, E.S.; Tomer, Y. Shared molecular amino acid signature in the HLA-DR peptide binding pocket predisposes to both autoimmune diabetes and thyroiditis. PNAS, 2010, 107, 16899-16903.

[32] Simmonds, M.J.; Howson, J.M.M.; Heward, J.M.; Carr-Smith, J.; Franklyn, J.A.; Todd, J.A.; Gough, S.C.L. A novel and major association of HLA-C in Graves' disease that eclipses the classical HLA-DRB1 effect. Hum. Mol. Genet., 2007, 16, 2149-2153.

[33] Weetman, A.P.; Zhang, L.; Webb, S.; Shine, B. Analysis of HLADQB and HLA-DPB alleles in Graves' disease by oligonucleotide probing of enzymatically amplified DNA. Clin. Endocrinol. (Oxf), 1990, 33, 65-71.

[34] Ratanachaiyavong, S., McGregor, A.M. HLA-DPB1 polymorphisms on the MHC-extended haplotypes of families of patients with Graves' disease: two distinct HLA-DR17 haplotypes. Eur. J. Clin. Invest., 1994, 24, 309-315.

[35] Hunt, P.J.; Marshall, S.E.; Weetman, A.P.; Bunce, M.; Bell, J.I.; Wass, J.A.H.; Welsh, K.I. Histocompatibility leucocyte antigens and closely linked immunomodulatory genes in autoimmune thyroid disease. Clin. Endocrinol., 2001, 55, 491-499.

[36] Chen, P.L.; Fann, C.S.-J.; Chu, C.C.; Chang, C.C.; Chang, S.W.; Hsieh, H.Y.; Lin, M.; Yang, W.S.; Chang, T.C. Comprehensive genotyping in two homogeneous Graves' disease samples reveals major and novel HLA association alleles. PLoS ONE, 2011, 6, e16635.

[37] Sridama, V.; Hara, Y.; Fauchet, R.; DeGroot, L.J. HLA immunogenetic heterogeneity in black american patients with Graves' Disease. Arch. Intern. Med., 1987, 147, 229-231.

[38] Omar, M.A.; Hammond, M.G.; Desai, R.K.; Motala, A.A.; Aboo, N.; Seedat, M.A. HLA class I and II antigens in South African blacks with Graves' disease. Clin. Immunol. Immunopathol., 1990, 54, 98-102.

[39] Ofosu, M.H.; Dunston, G.; Henry, L.; Ware, D.; Cheatham, W.; Brembridge, A.; Brown, C.; Alarif, L. HLA-DQ3 is associated with Graves' disease in African-Americans. Immunol. Invest., 1996, 25, 103-110.

[40] Yanagawa, T.; DeGroot, L.J. HLA class II associations in AfricanAmerican female patients with Graves' disease. Thyroid, 1996, 6, 37-39.

[41] Chen, Q.Y.; Nadell, D.; Zhang, X.Y.; Kukreja, A.; Huang, Y.J.; Wise, J.; Svec, F.; Richards, R.; Friday, K.E.; Vargas, A.; Gomez, R.; Chalew, S.; Lan, M.S.; Tomer, Y.; Maclaren, N.K. The Human Leukocyte Antigen HLA DRB3*0202/DQA1*0501 Haplotype is associated with Graves' Disease in African Americans. J. Clin. Endocrinol. Metab., 2000, 85, 1545-1549.

[42] Smikle, M.F.; Pascoe, R.W.; Barton, E.; Morgan, O.; Christian, N.; Dowe, G.; Roye-Green, K.; Bailey, V.; James, O. HLADRB3*0101 is associated with Graves' disease in Jamaicans. Clin. Endocrinol., 2001, 55, 805-808. 
[43] Bottini, N.; Musumeci, L.; Alonso, A.; Rahmouni, S.; Nika, K.; Rostamkhani, M.; MacMurray, J.; Meloni, G.F.; Lucarelli, P.; Pellecchia, M.; Eisenbarth, G.S.; Comings, D.; Mustelin, T. A functional variant of lymphoid tyrosine phosphatase is associated with type I diabetes. Nat. Genet., 2004, 36, 337-338.

[44] Smyth, D.; Cooper, J.D.; Collins, J.E.; Heward, J.M.; Franklyn, J.A.; Howson, J.M.; Vella, A.; Nutland, S.; Rance, H.E.; Maier, L.; Barratt, B.J.; Guja, C.; Ionescu-Tirgoviste, C.; Savage, D.A.; Dunger, D.B.; Widmer, B.; Strachan, D.P.; Ring, S.M.; Walker, N.; Clayton, D.G.; Twells, R.C.; Gough, S.C.; Todd, J.A. Replication of an association between the lymphoid tyrosine phosphatase locus (LYP/PTPN22) with type 1 diabetes, and evidence for its role as a general autoimmunity locus. Diabetes, 2004, 53, 3020-3023.

[45] Lee, Y.H.; Rho, Y.H.; Choi, S.J.; Ji, J.D.; Song, G.G.; Nath, S.K.; Harley, J.B. The PTPN22 C1858T functional polymorphism and autoimmune diseases--a meta-analysis. Rheumatology, 2007, 46, 49-56.

[46] Cohen, S.; Dadi, H.; Shaoul, E.; Sharfe, N.; Roifman, C.M. Cloning and characterization of a lymphoid-specific, inducible human protein tyrosine phosphatase, Lyp. Blood, 1999, 93, 20132024.

[47] Cloutier, J.F.; Veillette, A. Cooperative inhibition of T-cell antigen receptor signaling by a complex between a kinase and a phosphatase. J. Exp. Med., 1999, 189, 111-121.

[48] Begovich, A.B.; Carlton, V.E.H.; Honigberg, L.A.; Schrodi, S.J.; Chokkalingam, A.P.; Alexander, H.C.; Ardlie, K.G.; Huang, Q.; Smith, A.M.; Spoerke, J.M.; Conn, M.T.; Chang, M.; Chang, S.Y.; Saiki, R.K.; Catanese, J.J.; Leong, D.U.; Garcia, V.E.; McAllister, L.B.; Jeffery, D.A.; Lee, A.T.; Batliwalla, F.; Remmers, E.; Criswell, L.A.; Seldin, M.F.; Kastner, D.L.; Amos, C.I.; Sninsky, J.J.; Gregersen, P.K. A missense single-nucleotide polymorphism in a gene encoding a protein tyrosine phosphatase (PTPN22) is associated with rheumatoid arthritis. Am. J. Hum. Genet., 2004, 75, 330-337.

[49] Vang, T.; Congia, M.; Macis, M.D.; Musumeci, L.; Orru, V.; Zavattari, P.; Nika, K.; Tautz, L.; Tasken, K.; Cucca, F.; Mustelin, T.; Bottini, N. Autoimmune-associated lymphoid tyrosine phosphatase is a gain-of-function variant. Nat. Genet., 2005, 37, 1317-1319.

[50] Rieck, M.; Arechiga, A.; Onengut-Gumuscu, S.; Greenbaum, C.; Concannon, P.; Buckner, J.H. Genetic variation in PTPN22 corresponds to altered function of $\mathrm{T}$ and B lymphocytes. $J$. Immunol., 2007, 179, 4704-4710.

[51] Hasegawa, K.; Martin, F.; Huang, G.; Tumas, D.; Diehl, L.; Chan, A.C. Pest domain-enriched tyrosine phosphatase (PEP) regulation of effector/memory t cells. Science, 2004, 303, 685-689.

[52] Lefvert, A.K.; Zhao, Y.; Ramanujam, R.; Yu, S.; Pirskanen, R.; Hammarstrom, L. PTPN22 R620W promotes production of antiAChR autoantibodies and IL-2 in myasthenia gravis. $J$. Neuroimmunol., 2008, 197, 110-113.

[53] Gregersen, P.K.; Lee, H.S.; Batliwalla, F.; Begovich, A.B. PTPN22: setting thresholds for autoimmunity. Semin. Immunol., 2006, 18, 214-223.

[54] Arechiga, A.F.; Habib, T.; He, Y.; Zhang, X.; Zhang, Z.Y.; Funk, A.; Buckner, J.H. Cutting Edge: The PTPN22 Allelic Variant Associated with Autoimmunity Impairs B Cell Signaling. J. Immunol., 2009, 182, 3343-3347.

[55] Siggs, O.M.; Miosge, L.A.; Yates, A.L.; Kucharska, E.M.; Sheahan, D.; Brdicka, T.; Weiss, A.; Liston, A.; Goodnow, C.C. Opposing Functions of the T Cell Receptor Kinase ZAP-70 in Immunity and Tolerance Differentially Titrate in Response to Nucleotide Substitutions. Immunity, 2007, 27, 912-926.

[56] Stanford, S.M.; Mustelin, T.M.; Bottini, N. Lymphoid tyrosine phosphatase and autoimmunity: human genetics rediscovers tyrosine phosphatases. Semin. Immunopathol., 2010, 32, 127-136.

[57] Skorka, A.; Bednarczuk, T.; Bar-Andziak, E.; Nauman, J.; Ploski, R. Lymphoid tyrosine phosphatase (PTPN22/LYP) variant and Graves' disease in a Polish population: association and gene dosedependent correlation with age of onset. Clin. Endocrinol. (Oxf), 2005, 62, 679-682.

[58] Velaga, M.R.; Wilson, V.; Jennings, C.E.; Owen, C.J.; Herington, S.; Donaldson, P.T.; Ball, S.G.; James, R.A.; Quinton, R.; Perros, P.; Pearce, S.H.S. The codon 620 tryptophan allele of the lymphoid tyrosine phosphatase (LYP) gene is a major determinant of graves' disease. J. Clin. Endocrinol. Metab., 2004, 89, 5862-5865.
[59] Zhebrun, D.; Kudryashova, Y.; Babenko, A.; Maslyansky, A.; Kunitskaya, N.; Popcova, D.; Klushina, A.; Grineva, E.; Kostareva, A.; Shlyakhto, E. Association of PTPN22 1858T/T genotype with type 1 diabetes, Graves' disease but not with rheumatoid arthritis in Russian population. Aging (Albany.NY), 2011.

[60] Zeitlin, A.A.; Heward, J.M.; Brand, O.J.; Newby, P.R.; Franklyn, J.A.; Gough, S.C.L.; Simmonds, M.J. Use of Tag single nucleotide polymorphisms (SNPs) to screen PTPN21: no association with GravesGÇÖ disease. Clin. Endocrinol., 2006, 65, 380-384.

[61] Zhang, J.; Feuk, L.; Duggan, G.E.; Khaja, R.; Scherer, S.W. Development of bioinformatics resources for display and analysis of copy number and other structural variants in the human genome. Cytogenet. Genome Res., 2006, 115, 205-214.

[62] Huber, A.K.; Concepcion, E.S.; Gandhi, A.; Menconi, F.; Smith, E.P.; Keddache, M.; Tomer, Y. Analysis of immune regulatory genes' copy number variants in Graves' disease. Thyroid, 2011, 21 , 69-74.

[63] Orru, V.; Tsai, S.J.; Rueda, B.; Fiorillo, E.; Stanford, S.M.; Dasgupta, J.; Hartiala, J.; Zhao, L.; Ortego-Centeno, N.; D'Alfonso, S.; The Italian Collaborative Group; Arnett, F.C.; Wu, H.; Gonzalez-Gay, M.A.; Tsao, B.P.; Pons-Estel, B.; AlarconRiquelme, M.E.; He, Y.; Zhang, Z.Y.; Allayee, H.; Chen, X.S.; Martin, J.; Bottini, N. A loss-of-function variant of PTPN22 is associated with reduced risk of systemic lupus erythematosus. Hum. Mol. Genet., 2009, 18, 569-579.

[64] Heward, J.M.; Brand, O.J.; Barrett, J.C.; Carr-Smith, J.D.; Franklyn, J.A.; Gough, S.C. Association of PTPN22 haplotypes with Graves' disease. J. Clin. Endocrinol. Metab., 2007, 92, 685690.

[65] Carlton, V.E.H.; Hu, X.; Chokkalingam, A.P.; Schrodi, S.J.; Brandon, R.; Alexander, H.C.; Chang, M.; Catanese, J.J.; Leong, D.U.; Ardlie, K.G.; Kastner, D.L.; Seldin, M.F.; Criswell, L.A.; Gregersen, P.K.; Beasley, E.; Thomson, G.; Amos, C.I.; Begovich, A.B. PTPN22 genetic variation: evidence for multiple variants associated with rheumatoid arthritis. Am. J. Hum. Genet., 2005, 77, 567-581.

[66] Zhang, Z.H.; Chen, F.; Zhang, X.L.; Jin, Y.; Bai, J.; Fu, S.B. PTPN22 allele polymorphisms in 15 Chinese populations. Int. J. Immunogenet., 2008, 35, 433-437.

[67] Mori, M.; Yamada, R.; Kobayashi, K.; Kawaida, R.; Yamamoto, K. Ethnic differences in allele frequency of autoimmune-diseaseassociated SNPs. J. Hum. Genet., 2005, 50, 264-266.

[68] Ban, Y.; Tozaki, T.; Taniyama, M.; Tomita, M.; Ban, Y. The codon 620 single nucleotide polymorphism of the protein tyrosine phosphatase-22 gene does not contribute to autoimmune thyroid disease susceptibility in the Japanese. Thyroid, 2005, 15, 11151118.

[69] Ban, Y.; Tozaki, T.; Taniyama, M.; Nakano, Y.; Ban, Y.; Ban, Y.; Hirano, T. Association of the protein tyrosine phosphatase nonreceptor 22 haplotypes with autoimmune thyroid disease in the Japanese population. Thyroid, 2010, 0 .

[70] Tomer, Y.; Concepcion, E.; Greenberg, D.A. A C/T SingleNucleotide polymorphism in the region of the CD40 gene is associated with Graves' Disease. Thyroid, 2002, 12, 1129-1135.

[71] Jacobson, E.M.; Concepcion, E.; Oashi, T.; Tomer, Y. A graves' disease-associated kozak sequence single-nucleotide polymorphism enhances the efficiency of CD40 gene translation: A case for translational pathophysiology. Endocrinology, 2005, 146, 26842691.

[72] Heward, J.M.; Simmonds, M.J.; Carr-Smith, J.; Foxall, H.; Franklyn, J.A.; Gough, S.C. A single nucleotide polymorphism in the CD40 gene on chromosome 20q (GD-2) provides no evidence for susceptibility to Graves' disease in UK Caucasians. Clin. Endocrinol. (Oxf), 2004, 61, 269-272.

[73] Houston, F.A.; Wilson, V.; Jennings, C.E.; Owen, C.J.; Donaldson, P.; Perros, P.; Pearce, S.H.S. Role of the CD40 locus in graves' disease. Thyroid, 2004, 14, 506-509.

[74] Kurylowicz, A.; Kula, D.; Ploski, R.; Skorka, A.; JureckaLubieniecka, B.; Zebracka, J.; Steinhof-Radwanska, K.; HasseLazar, K.; Hiromatsu, Y.; Jarzab, B.; Bednarczuk, T. Association of CD40 gene polymorphism (C-1T) with susceptibility and phenotype of Graves' disease. Thyroid, 2005, 15, 1119-1124.

[75] Mukai, T.; Hiromatsu, Y.; Fukutani, T.; Ichimura, M.; Kaku, H.; Miyake, I.; Yamada, K. A C/T polymorphism in the 5' untranslated region of the CD40 gene is associated with later onset of graves' disease in Japanese. Endocr. J., 2005, 52, 471-477. 
[76] Ban, Y.; Tozaki, T.; Taniyama, M.; Tomita, M.; Ban, Y. Association of a $\mathrm{C} / \mathrm{T}$ single-nucleotide polymorphism in the $5^{\prime}$ untranslated region of the CD40 gene with graves' disease in Japanese. Thyroid, 2006, 16, 443-446.

[77] Caux, C.; Massacrier, C.; Vanbervliet, B.; Dubois, B.; Van Kooten, C.; Durand, I.; Banchereau, J. Activation of human dendritic cells through CD40 cross-linking. J. Exp. Med., 1994, 180, 1263-1272.

[78] Metcalfe, R.A.; McIntosh, R.S.; Marelli-Berg, F.; Lombardi, G.; Lechler, R.; Weetman, A.P. Detection of CD40 on human thyroid follicular cells: analysis of expression and function. J. Clin. Endocrinol. Metab., 1998, 83, 1268-1274.

[79] Smith, T.J.; Sempowski, G.D.; Berenson, C.S.; Cao, H.J.; Wang, H.S.; Phipps, R.P. Human thyroid fibroblasts exhibit a distinctive phenotype in culture: characteristic ganglioside profile and functional CD40 expression. Endocrinology, 1997, 138, 55765588 .

[80] Clark, L.B.; Foy, T.M.; Noelle, R.J. CD40 and its ligand. Adv. Immunol., 1996, 63, 43-78.

[81] Chatzigeorgiou, A.; Lyberi, M.; Chatzilymperis, G.; Nezos, A.; Kamper, E. CD40/CD40L signaling and its implication in health and disease. Biofactors, 2009, 35, 474-483.

[82] Hollenbaugh, D.; Grosmaire, L.S.; Kullas, C.D.; Chalupny, N.J.; Braesch-Andersen, S.; Noelle, R.J.; Stamenkovic, I.; Ledbetter, J.A.; Aruffo, A. The human T cell antigen gp39, a member of the TNF gene family, is a ligand for the CD40 receptor: expression of a soluble form of gp39 with B cell co-stimulatory activity. EMBO J., 1992, 11, 4313-4321.

[83] Ye, F.; Shi, B.; Wu, X.; Hou, P.; Gao, L.; Ma, X.; Xu, L.; Wu, L. Experience with lentivirus-mediated CD40 gene silencing in a mouse model of Graves' disease. J. Endocrinol., 2011, 208, 285291.

[84] Puck, J.M.; Willard, H.F. X inactivation in females with X-linked disease. N. Engl. J. Med., 1998, 338, 325-328.

[85] Walunas, T.L.; Bakker, C.Y.; Bluestone, J.A. CTLA-4 ligation blocks CD28-dependent T cell activation. J. Exp. Med., 1996, 183, 2541-2550.

[86] Gough, S.C.; Walker, L.S.; Sansom, D.M. CTLA4 gene polymorphism and autoimmunity. Immunol. Rev., 2005, 204, 102115.

[87] Schneider, H.; Downey, J.; Smith, A.; Zinselmeyer, B.H.; Rush, C.; Brewer, J.M.; Wei, B.; Hogg, N.; Garside, P.; Rudd, C.E. Reversal of the TCR stop signal by CTLA-4. Science, 2006, 313, 1972-1975.

[88] Downey, J.; Smith, A.; Schneider, H.; Hogg, N.; Rudd, C.E. TCR/CD3 mediated stop-signal is decoupled in T-cells from Ctla4 deficient mice. Immunol. Lett., 2008, 115, 70-72.

[89] Schneider, H.; Smith, X.; Liu, H.; Bismuth, G.; Rudd, C.E. CTLA4 disrupts ZAP70 microcluster formation with reduced T cell/APC dwell times and calcium mobilization. Eur. J. Immunol., 2008, 38, 40-47.

[90] Buemann, B.; Astrup, A. How does the body deal with energy from alcohol? Nutrition, 2001, 17, 638-641.

[91] Oaks, M.K.; Hallett, K.M. Cutting edge: a soluble form of CTLA-4 in patients with autoimmune thyroid disease. J. Immunol., 2000, 164, 5015-5018.

[92] Liu, M.F.; Wang, C.R.; Chen, P.C.; Fung, L.L. Increased expression of soluble cytotoxic T-lymphocyte-associated antigen-4 molecule in patients with systemic lupus erythematosus. Scand. J. Immunol., 2003, 57, 568-572.

[93] Qureshi, O.S.; Zheng, Y.; Nakamura, K.; Attridge, K.; Manzotti, C.; Schmidt, E.M.; Baker, J.; Jeffery, L.E.; Kaur, S.; Briggs, Z.; Hou, T.Z.; Futter, C.E.; Anderson, G.; Walker, L.S.; Sansom, D.M. Trans-endocytosis of CD80 and CD86: a molecular basis for the cell-extrinsic function of CTLA-4. Science, 2011, 332, 600-603.

[94] Yanagawa, T.; Hidaka, Y.; Guimaraes, V.; Soliman, M.; DeGroot, L.J. CTLA-4 gene polymorphism associated with Graves' disease in a Caucasian population. J. Clin. Endocrinol. Metab., 1995, 80, 41-45.

[95] Donner, H.; Rau, H.; Walfish, P.G.; Braun, J.; Siegmund, T.; Finke, R.; Herwig, J.; Usadel, K.H.; Badenhoop, K. CTLA4 alanine-17 confers genetic susceptibility to Graves' disease and to type 1 diabetes mellitus. J. Clin. Endocrinol. Metab., 1997, 82, 143-146.

[96] Takara, M.; Kouki, T.; DeGroot, L.J. CTLA-4 AT-repeat polymorphism reduces the inhibitory function of CTLA-4 in Graves' disease. Thyroid, 2003, 13, 1083-1089.

[97] Chistiakov, D.A.; Savost'anov, K.V.; Turakulov, R.I.; Efremov, I.A.; Demurov, L.M. Genetic analysis and functional evaluation of the $\mathrm{C} / \mathrm{T}(-318)$ and $\mathrm{A} / \mathrm{G}(-1661)$ polymorphisms of the CTLA-4 gene in patients affected with Graves' disease. Clin. Immunol., 2006 $118,233-242$.

[98] Heward, J.M.; Allahabadia, A.; Armitage, M.; Hattersley, A.; Dodson, P.M.; Macleod, K.; Carr-Smith, J.; Daykin, J.; Daly, A.; Sheppard, M.C.; Holder, R.L.; Barnett, A.H.; Franklyn, J.A.; Gough, S.C. The development of Graves' disease and the CTLA-4 gene on chromosome 2q33. J. Clin. Endocrinol. Metab., 1999, 84 2398-2401.

[99] Chistyakov, D.A.; Savost'anov, K.V.; Turakulov, R.I.; Petunina, N.A.; Trukhina, L.V.; Kudinova, A.V.; Balabolkin, M.I.; Nosikov, V.V. Complex association analysis of Graves disease using a set of polymorphic markers. Mol. Genet. Metab., 2000, 70, 214-218.

[100] Kouki, T.; Gardine, C.A.; Yanagawa, T.; DeGroot, L.J. Relation of three polymorphisms of the CTLA-4 gene in patients with Graves' disease. J. Endocrinol. Invest., 2002, 25, 208-213.

[101] Ban, Y.; Concepcion, E.S.; Villanueva, R.; Greenberg, D.A.; Davies, T.F.; Tomer, Y. Analysis of immune regulatory genes in familial and sporadic Graves' disease. J. Clin. Endocrinol. Metab., 2004, $89,4562-4568$.

[102] Furugaki, K.; Shirasawa, S.; Ishikawa, N.; Ito, K.; Ito, K.; Kubota, S.; Kuma, K.; Tamai, H.; Akamizu, T.; Hiratani, H.; Tanaka, M.; Sasazuki, T. Association of the T-cell regulatory gene CTLA4 with Graves' disease and autoimmune thyroid disease in the Japanese. $J$. Hum. Genet., 2004, 49, 166-168.

[103] Vaidya, B.; Imrie, H.; Perros, P.; Young, E.T.; Kelly, W.F.; Carr, D.; Large, D.M.; Toft, A.D.; McCarthy, M.I.; Kendall-Taylor, P.; Pearce, S.H. The cytotoxic T lymphocyte antigen-4 is a major Graves' disease locus. Hum. Mol. Genet., 1999, 8, 1195-1199.

[104] Anjos, S.; Nguyen, A.; Ounissi-Benkalha, H.; Tessier, M.C. Polychronakos, C. A common autoimmunity predisposing signal peptide variant of the cytotoxic T-lymphocyte antigen 4 results in inefficient glycosylation of the susceptibility allele. J. Biol. Chem., 2002, 277, 46478-46486.

[105] Xu, Y.; Graves, P.N.; Tomer, Y.; Davies, T.F. CTLA-4 and autoimmune thyroid disease: lack of influence of the A49G signal peptide polymorphism on functional recombinant human CTLA-4 Cell Immunol., 2002, 215, 133-140.

[106] Daroszewski, J.; Pawlak, E.; Karabon, L.; Frydecka, I.; Jonkisz, A.; Slowik, M.; Bolanowski, M. Soluble CTLA-4 receptor an immunological marker of Graves' disease and severity of ophthalmopathy is associated with CTLA-4 Jo31 and CT60 gene polymorphisms. Eur. J. Endocrinol., 2009, 161, 787-793.

[107] Petrone, A.; Giorgi, G.; Galgani, A.; Alemanno, I.; Corsello, S.M.; Signore, A.; Di Mario, U.; Nistico, L.; Cascino, I.; Buzzetti, R. CT60 single nucleotide polymorphisms of the cytotoxic Tlymphocyte-associated antigen-4 gene region is associated with Graves' disease in an Italian population. Thyroid, 2005, 15, 232238.

[108] Ban, Y.; Tozaki, T.; Taniyama, M.; Tomita, M.; Ban, Y. Association of a CTLA-4 3' untranslated region (CT60) single nucleotide polymorphism with autoimmune thyroid disease in the Japanese population. Autoimmunity, 2005, 38, 151-153

[109] Ueda, H.; Howson, J.M.; Esposito, L.; Heward, J.; Snook, H.; Chamberlain, G.; Rainbow, D.B.; Hunter, K.M.; Smith, A.N.; Di Genova, G.; Herr, M.H.; Dahlman, I.; Payne, F.; Smyth, D.; Lowe, C.; Twells, R.C.; Howlett, S.; Healy, B.; Nutland, S.; Rance, H.E.; Everett, V.; Smink, L.J.; Lam, A.C.; Cordell, H.J.; Walker, N.M.; Bordin, C.; Hulme, J.; Motzo, C.; Cucca, F.; Hess, J.F.; Metzker, M.L.; Rogers, J.; Gregory, S.; Allahabadia, A.; Nithiyananthan, R.; Tuomilehto-Wolf, E.; Tuomilehto, J.; Bingley, P.; Gillespie, K.M.; Undlien, D.E.; Ronningen, K.S.; Guja, C.; Ionescu-Tirgoviste, C.; Savage, D.A.; Maxwell, A.P.; Carson, D.J.; Patterson, C.C.; Franklyn, J.A.; Clayton, D.G.; Peterson, L.B.; Wicker, L.S.; Todd, J.A.; Gough, S.C. Association of the T-cell regulatory gene CTLA4 with susceptibility to autoimmune disease. Nature, 2003, 423, 506511.

[110] Magistrelli, G.; Jeannin, P.; Herbault, N.; Benoit, D.C.; Gauchat, J.F.; Bonnefoy, J.Y.; Delneste, Y. A soluble form of CTLA-4 generated by alternative splicing is expressed by nonstimulated human T cells. Eur. J. Immunol., 1999, 29, 3596-3602.

[111] Mayans, S.; Lackovic, K.; Nyholm, C.; Lindgren, P.; Ruikka, K.; Eliasson, M.; Cilio, C.M.; Holmberg, D. CT60 genotype does not affect CTLA-4 isoform expression despite association to T1D and AITD in northern Sweden. BMC. Med. Genet., 2007, 8, 3. 
[112] Takahashi, M.; Kimura, A. HLA and CTLA4 polymorphisms may confer a synergistic risk in the susceptibility to Graves' disease. $J$. Hum. Genet., 2010, 55, 323-326.

[113] Kavvoura, F.K.; Akamizu, T.; Awata, T.; Ban, Y.; Chistiakov, D.A.; Frydecka, I.; Ghaderi, A.; Gough, S.C.; Hiromatsu, Y.; Ploski, R.; Wang, P.W.; Ban, Y.; Bednarczuk, T.; Chistiakova, E.I.; Chojm, M.; Heward, J.M.; Hiratani, H.; Juo, S.H.; Karabon, L.; Katayama, S.; Kurihara, S.; Liu, R.T.; Miyake, I.; Omrani, G.H.; Pawlak, E.; Taniyama, M.; Tozaki, T.; Ioannidis, J.P. Cytotoxic Tlymphocyte associated antigen 4 gene polymorphisms and autoimmune thyroid disease: a meta-analysis. J. Clin. Endocrinol. Metab., 2007, 92, 3162-3170.

[114] Weetman, A.P. Graves' disease by any other name? Thyroid, 2000, 10, 1071-1072.

[115] Akamizu, T.; Ikuyama, S.; Saji, M.; Kosugi, S.; Kozak, C.; McBride, O.W.; Kohn, L.D. Cloning, chromosomal assignment, and regulation of the rat thyrotropin receptor: expression of the gene is regulated by thyrotropin, agents that increase cAMP levels, and thyroid autoantibodies. Proc. Natl. Acad. Sci. USA, 1990, 87, 5677-5681.

[116] Rousseau-Merck, M.F.; Misrahi, M.; Loosfelt, H.; Atger, M.; Milgrom, E.; Berger, R. Assignment of the human thyroid stimulating hormone receptor (TSHR) gene to chromosome $14 \mathrm{q} 31$. Genomics, 1990, 8, 233-236.

[117] Kakinuma, A.; Nagayama, Y. Multiple messenger ribonucleic acid transcripts and revised gene organization of the human TSH receptor. Endocr. J., 2002, 49, 175-180.

[118] Gustavsson, B.; Eklof, C.; Westermark, K.; Westermark, B.; Heldin, N.E. Functional analysis of a variant of the thyrotropin receptor gene in a family with Graves' disease. Mol. Cell Endocrinol., 1995, 111, 167-173.

[119] Chistiakov, D.A.; Savost'anov, K.V.; Turakulov, R.I. Screening of SNPs at 18 positional candidate genes, located within the GD-1 locus on chromosome 14q23-q32, for susceptibility to Graves' disease: a TDT study. Mol. Genet. Metab., 2004, 83, 264-270.

[120] Chistiakov, D.A.; Savost'anov, K.V.; Turakulov, R.I.; Petunina, N.; Balabolkin, M.I.; Nosikov, V.V. Further studies of genetic susceptibility to Graves' disease in a Russian population. Med. Sci. Monit., 2002, 8, CR180-CR184.

[121] Ban, Y.; Greenberg, D.A.; Concepcion, E.S.; Tomer, Y. A germline single nucleotide polymorphism at the intracellular domain of the human thyrotropin receptor does not have a major effect on the development of Graves' disease. Thyroid, 2002, 12, 1079-1083.

[122] Simanainen, J.; Kinch, A.; Westermark, K.; Winsa, B.; Bengtsson, M.; Schuppert, F.; Westermark, B.; Heldin, N.E. Analysis of mutations in exon 1 of the human thyrotropin receptor gene: High frequency of the $\mathrm{D} 36 \mathrm{H}$ and $\mathrm{P} 52 \mathrm{~T}$ polymorphic variants. Thyroid, 1999, 9, 7-11.

[123] Kaczur, V.; Takacs, M.; Szalai, C.; Falus, A.; Nagy, Z.; Berencsi, G.; Balazs, C. Analysis of the genetic variability of the 1st (CCC/ACC, P52T) and the 10th exons (bp 1012-1704) of the TSH receptor gene in Graves' disease. Eur. J. Immunogenet., 2000, 27, 17-23.

[124] de Roux, N.; Shields, D.C.; Misrahi, M.; Ratanachaiyavong, S.; McGregor, A.M.; Milgrom, E. Analysis of the thyrotropin receptor as a candidate gene in familial Graves' disease. J. Clin. Endocrinol. Metab., 1996, 81, 3483-3486.

[125] Tomer, Y.; Ban, Y.; Concepcion, E.; Barbesino, G.; Villanueva, R.; Greenberg, D.A.; Davies, T.F. Common and unique susceptibility loci in Graves and Hashimoto diseases: results of whole-genome screening in a data set of 102 multiplex families. Am. J. Hum. Genet., 2003, 73, 736-747.

[126] Akamizu, T.; Sale, M.M.; Rich, S.S.; Hiratani, H.; Noh, J.Y.; Kanamoto, N.; Saijo, M.; Miyamoto, Y.; Saito, Y.; Nakao, K.; Bowden, D.W. Association of autoimmune thyroid disease with microsatellite markers for the thyrotropin receptor gene and CTLA4 in Japanese patients. Thyroid, 2000, 10, 851-858.

[127] Hiratani, H.; Bowden, D.W.; Ikegami, S.; Shirasawa, S.; Shimizu, A.; Iwatani, Y.; Akamizu, T. Multiple SNPs in intron 7 of thyrotropin receptor are associated with graves' disease. J. Clin. Endocrinol. Metab., 2005, 90, 2898-2903.

[128] Dechairo, B.M.; Zabaneh, D.; Collins, J.; Brand, O.; Dawson, G.J.; Green, A.P.; Mackay, I.; Franklyn, J.A.; Connell, J.M.; Wass, J.A.; Wiersinga, W.M.; Hegedus, L.; Brix, T.; Robinson, B.G.; Hunt, P.J.; Weetman, A.P.; Carey, A.H.; Gough, S.C. Association of the
TSHR gene with Graves' disease: the first disease specific locus. Eur. J. Hum. Genet., 2005, 13, 1223-1230.

[129] Brand, O.J.; Barrett, J.C.; Simmonds, M.J.; Newby, P.R.; McCabe, C.J.; Bruce, C.K.; Kysela, B.; Carr-Smith, J.D.; Brix, T.; Hunt, P.J.; Wiersinga, W.M.; Hegedus, L.; Connell, J.; Wass, J.A.H.; Franklyn, J.A.; Weetman, A.P.; Heward, J.M.; Gough, S.C.L. Association of the thyroid stimulating hormone receptor gene (TSHR) with Graves' disease. Hum. Mol. Genet., 2009, 18, 17041713.

[130] Chen, C.R.; Pichurin, P.; Nagayama, Y.; Latrofa, F.; Rapoport, B.; McLachlan, S.M. The thyrotropin receptor autoantigen in Graves disease is the culprit as well as the victim. J. Clin. Invest., 2003, 111, 1897-1904.

[131] Ploski, R.; Brand, O.J.; Jurecka-Lubieniecka, B.; Franaszczyk, M.; Kula, D.; Krajewski, P.; Karamat, M.A.; Simmonds, M.J.; Franklyn, J.A.; Gough, S.C.; Jarzab, B.; Bednarczuk, T. Thyroid stimulating hormone receptor (TSHR) intron 1 variants are major risk factors for Graves' disease in three European Caucasian cohorts. PLOS ONE, 2010, 5, e15512.

[132] Ho, S.C.; Goh, S.S.; Khoo, D.H. Association of Graves' disease with intragenic polymorphism of the thyrotropin receptor gene in a cohort of Singapore patients of multi-ethnic origins. Thyroid, 2003, $13,523-528$

[133] Wellcome Trust Case Control Consortium, Australo-AngloAmerican Spondylitis Consortium (TASC) Association scan of 14,500 nonsynonymous SNPs in four diseases identifies autoimmunity variants. Nat. Genet., 2007, 39, 1329-1337.

[134] Sakai, K.; Shirasawa, S.; Ishikawa, N.; Ito, K.; Tamai, H.; Kuma, K.; Akamizu, T.; Tanimura, M.; Furugaki, K.; Yamamoto, K.; Sasazuki, T. Identification of susceptibility loci for autoimmune thyroid disease to 5q31-q33 and Hashimoto's thyroiditis to 8q23q24 by multipoint affected sib-pair linkage analysis in Japanese. Hum. Mol. Genet., 2001, 10, 1379-1386.

[135] Ban, Y.; Greenberg, D.A.; Davies, T.F.; Jacobson, E.; Concepcion, E.; Tomer, Y. 'Linkage analysis of thyroid antibody production: evidence for shared susceptibility to clinical autoimmune thyroid disease. J. Clin. Endocrinol. Metab., 2008, 93, 3589-3596.

[136] Collins, J.E.; Heward, J.M.; Carr-Smith, J.; Daykin, J.; Franklyn, J.A.; Gough, S.C. Association of a rare thyroglobulin gene microsatellite variant with autoimmune thyroid disease. J. Clin. Endocrinol. Metab., 2003, 88, 5039-5042.

[137] Ban, Y.; Greenberg, D.A.; Concepcion, E.; Skrabanek, L.; Villanueva, R.; Tomer, Y. Amino acid substitutions in the thyroglobulin gene are associated with susceptibility to human and murine autoimmune thyroid disease. Proc. Natl. Acad. Sci. USA, 2003, 100, 15119-15124.

[138] Maierhaba, M.; Zhang, J.A.; Yu, Z.Y.; Wang, Y.; Xiao, W.X.; Quan, Y.; Dong, B.N. Association of the thyroglobulin gene polymorphism with autoimmune thyroid disease in Chinese population. Endocrine, 2008, 33, 294-299.

[139] Caputo, M.; Rivolta, C.M.; Mories, T.; Corrales, J.J.; Galindo, P.; Gonzalez-Sarmiento, R.; Targovnik, H.M.; Miralles-Garcia, J.M. Analysis of thyroglobulin gene polymorphisms in patients with autoimmune thyroiditis. Endocrine, 2010, 37, 389-395.

[140] Varela, V.; Rizzo, L.; Domene, S.; Bruno, O.D.; Tellechea, M.L.; Rivolta, C.M.; Targovnik, H.M. Association of the TGrI29 microsatellite in thyroglobulin gene with autoimmune thyroiditis in a Argentinian population: a case-control study. Endocrine, 2010, 38, 320-327.

[141] Ban, Y.; Tozaki, T.; Taniyama, M.; Tomita, M.; Ban, Y. Association of a thyroglobulin gene polymorphism with Hashimoto's thyroiditis in the Japanese population. Clin. Endocrinol. (Oxf), 2004, 61, 263-268.

[142] Hsiao, J.Y.; Hsieh, M.C.; Tien, K.J.; Hsu, S.C.; Shin, S.J.; Lin, S.R Association between a $\mathrm{C} / \mathrm{T}$ polymorphism in exon 33 of the thyroglobulin gene is associated with relapse of Graves' hyperthyroidism after antithyroid withdrawal in Taiwanese. J. Clin. Endocrinol. Metab., 2007, 92, 3197-3201.

[143] Hsiao, J.Y.; Hsieh, M.C.; Hsiao, C.T.; Weng, H.H.; Ke, D.S. Association of CD40 and thyroglobulin genes with later-onset Graves' disease in Taiwanese patients. Eur. J. Endocrinol., 2008, $159,617-621$.

[144] Hsiao, J.Y.; Hsieh, M.C.; Tien, K.J.; Hsu, S.C.; Lin, S.R.; Ke, D.S. Exon $33 \mathrm{~T} / \mathrm{T}$ genotype of the thyroglobulin gene is a susceptibility gene for Graves' disease in Taiwanese and exon $12 \mathrm{C} / \mathrm{C}$ genotype protects against it. Clin. Exp. Med., 2008, 8, 17-21. 
[145] Gu, L.Q.; Zhu, W.; Zhao, S.X.; Zhao, L.; Zhang, M.J.; Cui, B.; Song, H.D.; Ning, G.; Zhao, Y.J. Clinical associations of the genetic variants of CTLA-4, Tg, TSHR, PTPN22, PTPN12 and FCRL3 in patients with Graves' disease. Clin. Endocrinol. (Oxf), 2010, 72, 248-255.

[146] Tanrikulu, S.; Erbil, Y.; Ademoglu, E.; Issever, H.; Barbaros, U.; Kutluturk, F.; Ozarmagan, S.; Tezelman, S. The predictive value of CTLA-4 and Tg polymorphisms in the recurrence of Graves' disease after antithyroid withdrawal. Endocrine, 2006, 30, 377-381.

[147] Collins, J.E.; Heward, J.M.; Howson, J.M.; Foxall, H.; Carr-Smith, J.; Franklyn, J.A.; Gough, S.C. Common allelic variants of exons 10,12 , and 33 of the thyroglobulin gene are not associated with autoimmune thyroid disease in the United Kingdom. J. Clin. Endocrinol. Metab., 2004, 89, 6336-6339.

[148] Wan, Q.; Shah, R.; Panos, J.C.; Giraldo, A.A.; David, C.S.; Kong, Y.M. HLA-DR and HLA-DQ polymorphism in human thyroglobulin-induced autoimmune thyroiditis: DR3 and DQ8 transgenic mice are susceptible. Hum. Immunol., 2002, 63, 301310.

[149] Menconi, F.; Huber, A.; Osman, R.; Concepcion, E.; Jacobson, E.M.; Stefan, M.; David, C.S.; Tomer, Y. Tg.2098 is a major human thyroglobulin T-cell epitope. J. Autoimmun., 2010, 35, 4551

[150] Jacobson, E.M.; Concepcion, E.; Ho, K.; Kopp, P.; Vono, T.J.; Tomer, Y. cDNA immunization of mice with human thyroglobulin generates both humoral and $\mathrm{T}$ cell responses: a novel model of thyroid autoimmunity. PLoS ONE, 2011, 6, e19200.

[151] Hodge, S.E.; Ban, Y.; Strug, L.J.; Greenberg, D.A.; Davies, T.F.; Concepcion, E.S.; Villanueva, R.; Tomer, Y. Possible interaction between HLA-DRbetal and thyroglobulin variants in Graves' disease. Thyroid, 2006, 16, 351-355.

[152] Stefan, M.; Jacobson, E.M.; Huber, A.K.; Greenberg, D.A.; Li, C.W.; Skrabanek, L.; Conception, E.; Fadlalla, M.; Ho, K.; Tomer, Y. A novel variant of the thyroglobulin promoter triggers thyroid autoimmunity through an epigenetic interferon alpha-modulated mechanism. J. Biol. Chem., 2011.

[153] Kochi, Y.; Yamada, R.; Suzuki, A.; Harley, J.B.; Shirasawa, S.; Sawada, T.; Bae, S.C.; Tokuhiro, S.; Chang, X.; Sekine, A.; Takahashi, A.; Tsunoda, T.; Ohnishi, Y.; Kaufman, K.M.; Kang, C.P.; Kang, C.; Otsubo, S.; Yumura, W.; Mimori, A.; Koike, T.; Nakamura, Y.; Sasazuki, T.; Yamamoto, K. A functional variant in FCRL3, encoding Fc receptor-like 3, is associated with rheumatoid arthritis and several autoimmunities. Nat. Genet., 2005, 37, 478485.

[154] Swainson, L.A.; Mold, J.E.; Bajpai, U.D.; McCune, J.M. Expression of the autoimmune susceptibility gene FcRL3 on human regulatory $\mathrm{t}$ cells is associated with dysfunction and high levels of programmed cell death-1. J. Immunol., 2010, 184, 36393647.

[155] Simmonds, M.J.; Heward, J.M.; Carr-Smith, J.; Foxall, H.; Franklyn, J.A.; Gough, S.C.L. Contribution of single nucleotide polymorphisms within FCRL3 and MAP3K7IP2 to the pathogenesis of graves' disease. J. Clin. Endocrinol. Metab., 2006, 91, 1056-1061.

[156] Owen, C.J.; Kelly, H.; Eden, J.A.; Merriman, M.E.; Pearce, S.H.S.; Merriman, T.R. Analysis of the Fc Receptor-Like-3 (FCRL3) locus in caucasians with autoimmune disorders suggests a complex pattern of disease association. J. Clin. Endocrinol. Metab., 2007, 92, 1106-1111.

[157] Simmonds, M.J.; Brand, O.J.; Barrett, J.C.; Newby, P.R.; Franklyn, J.A.; Gough, S.C. Association of Fc receptor-like 5 (FCRL5) with Graves' disease is secondary to the effect of FCRL3. Clin. Endocrinol. (Oxf), 2010, 73, 654-660.

[158] Song, H.D.; Liang, J.; Shi, J.Y.; Zhao, S.X.; Liu, Z.; Zhao, J.J.; Peng, Y.D.; Gao, G.Q.; Tao, J.; Pan, C.M.; Shao, L.; Cheng, F.; Wang, Y.; Yuan, G.Y.; Xu, C.; Han, B.; Huang, W.; Chu, X.; Chen, Y.; Sheng, Y.; Li, R.Y.; Su, Q.; Gao, L.; Jia, W.P.; Jin, L.; Chen, M.D.; Chen, S.J.; Chen, Z.; Chen, J.L. Functional SNPs in the SCGB3A2 promoter are associated with susceptibility to Graves' disease. Hum. Mol. Genet., 2009, 18, 1156-1170.

[159] Jin, Y.; Teng, W.; Ben, S.; Xiong, X.; Zhang, J.; Xu, S.; Shugart, Y.Y.; Jin, L.; Chen, J.; Huang, W. Genome-wide scan of Graves' disease: evidence for linkage on chromosome $5 \mathrm{q} 31$ in Chinese Han pedigrees. J. Clin. Endocrinol. Metab., 2003, 88, 1798-1803.

[160] Simmonds, M.J.; Yesmin, K.; Newby, P.R.; Brand, O.J.; Franklyn, J.A.; Gough, S.C.L. Confirmation of association of chromosome 5q31.33 with United Kingdom caucasian graves' disease. Thyroid, 2010, 20, 413-417.

[161] Chistiakov, D.A.; Voronova, N.V.; Turakulov, R.I.; Savost'anov, K.V. The $-112 \mathrm{G}>\mathrm{A}$ polymorphism of the secretoglobin $3 \mathrm{~A} 2$ (SCGB3A2) gene encoding uteroglobin-related protein 1 (UGRP1) increases risk for the development of Graves' disease in subsets of patients with elevated levels of immunoglobulin E. J. Appl. Genet., 2011, 52, 201-207.

[162] Yang, Y.; Lingling, S.; Ying, J.; Yushu, L.; Zhongyan, S.; Wei, H.; Weiping, T. Association study between the IL4, IL13, IRF1 and UGRP1 genes in chromosomal 5q31 region and Chinese Graves' disease. J. Hum. Genet., 2005, 50, 574-582.

[163] Niimi, T.; Munakata, M.; Keck-Waggoner, C.L.; Popescu, N.C.; Levitt, R.C.; Hisada, M.; Kimura, S. A polymorphism in the human UGRP1 gene promoter that regulates transcription is associated with an increased risk of asthma. Am. J. Hum. Genet., 2002, 70, 718-725.

[164] Inoue, K.; Wang, X.; Saito, J.; Tanino, Y.; Ishida, T.; Iwaki, D.; Fujita, T.; Kimura, S.; Munakata, M. Plasma UGRP1 levels associate with promoter G-112A polymorphism and the severity of asthma. Allergol. Int., 2008, 57, 57-64.

[165] Tomita, T.; Kido, T.; Kurotani, R.; Iemura, S.; Sterneck, E.; Natsume, T.; Vinson, C.; Kimura, S. CAATT/enhancer-binding proteins alpha and delta interact with NKX2-1 to synergistically activate mouse secretoglobin $3 \mathrm{~A} 2$ gene expression. J. Biol. Chem., 2008, 283, 25617-25627.

[166] Bin, L.H.; Nielson, L.D.; Liu, X.; Mason, R.J.; Shu, H.B. Identification of uteroglobin-related protein 1 and macrophage scavenger receptor with collagenous structure as a lung-specific ligand-receptor pair. J. Immunol., 2003, 171, 924-930.

[167] Areschoug, T.; Gordon, S. Scavenger receptors: role in innate immunity and microbial pathogenesis. Cell Microbiol., 2009, 11, 1160-1169.

[168] Kraal, G.; van der Laan, L.J.; Elomaa, O.; Tryggvason, K. The macrophage receptor MARCO. Microbes Infect., 2000, 2, 313-316.

[169] Thakur, S.A.; Beamer, C.A.; Migliaccio, C.T.; Holian, A. Critical role of MARCO in crystalline silica-induced pulmonary inflammation. Toxicol. Sci, 2009, 108, 462-471.

[170] Chu, X.; Dong, C.; Lei, R.; Sun, L.; Wang, Z.; Dong, Y.; Shen, M.; Wang, Y.; Wang, B.; Zhang, K.; Yang, L.; Li, Y.; Yuan, W.; Wang, Y.; Song, H.; Jin, L.; Xiong, M.; Huang, W. Polymorphisms in the interleukin 3 gene show strong association with susceptibility to Graves' disease in Chinese population. Genes Immun., 2009, 10, 260-266.

[171] Zhu, W.; Liu, N.; Zhao, Y.; Jia, H.; Cui, B.; Ning, G. Association analysis of polymorphisms in IL-3, IL-4, IL-5, IL-9, and IL-13 with Graves' disease. J. Endocrinol. Invest., 2010, 33, 751-755.

[172] Jazdzewski, K.; Bednarczuk, T.; Stepnowska, M.; Liyanarachchi, S.; Suchecka-Rachon, K.; Limon, J.; Narkiewicz, K. beta-2Adrenergic receptor gene polymorphism confers susceptibility to Graves disease. Int. J. Mol. Med., 2007, 19, 181-186.

[173] Chu, X.; Dong, Y.; Shen, M.; Sun, L.L.; Dong, C.Z.; Wang, Y.; Wang, B.L.; Zhang, K.Y.; Hua, Q.; Xu, S.J.; Huang, W. Polymorphisms in the ADRB2 gene and Graves disease: a casecontrol study and a meta-analysis of available evidence. $B M C$ Medical Genetics, 2009, 10.

[174] Todd, J.A.; Walker, N.M.; Cooper, J.D.; Smyth, D.J.; Downes, K.; Plagnol, V.; Bailey, R.; Nejentsev, S.; Field, S.F.; Payne, F.; Lowe, C.E.; Szeszko, J.S.; Hafler, J.P.; Zeitels, L.; Yang, J.H.M.; Vella, A.; Nutland, S.; Stevens, H.E.; Schuilenburg, H.; Coleman, G.; Maisuria, M.; Meadows, W.; Smink, L.J.; Healy, B.; Burren, O.S.; Lam, A.A.C.; Ovington, N.R.; Allen, J.; Adlem, E.; Leung, H.T.; Wallace, C.; Howson, J.M.M.; Guja, C.; Ionescu-Tirgoviste, C.; Simmonds, M.J.; Heward, J.M.; Gough, S.C.L.; Dunger, D.B.; Wicker, L.S.; Clayton, D.G. Robust associations of four new chromosome regions from genome-wide analyses of type 1 diabetes. Nat. Genet., 2007, 39, 857-864.

[175] van Heel, D.A.; Franke, L.; Hunt, K.A.; Gwilliam, R.; Zhernakova, A.; Inouye, M.; Wapenaar, M.C.; Barnardo, M.C.N.M.; Bethel, G.; Holmes, G.K.T.; Feighery, C.; Jewell, D.; Kelleher, D.; Kumar, P.; Travis, S.; Walters, J.R.; Sanders, D.S.; Howdle, P.; Swift, J.; Playford, R.J.; McLaren, W.M.; Mearin, M.L.; Mulder, C.J.; McManus, R.; McGinnis, R.; Cardon, L.R.; Deloukas, P.; Wijmenga, C. A genome-wide association study for celiac disease identifies risk variants in the region harboring IL2 and IL21. Nat. Genet., 2007, 39, 827-829. 
[176] Festen, E.A.M.; Goyette, P.; Scott, R.; Annese, V.; Zhernakova, A.; Lian, J.; Lef+Ębvre, C.; Brant, S.R.; Cho, J.H.; Silverberg, M.S.; Taylor, K.D.; de Jong, D.J.; Stokkers, P.C.; Mcgovern, D.; Palmieri, O.; Achkar, J.P.; Xavier, R.J.; Daly, M.J.; Duerr, R.H.; Wijmenga, C.; Weersma, R.K.; Rioux, J.D. Genetic variants in the region harbouring IL2/IL21 associated with ulcerative colitis. Gut, 2009, $58,799-804$.

[177] Zhernakova, A.; Alizadeh, B.Z.; Bevova, M.; van Leeuwen, M.A.; Coenen, M.J.H.; Franke, B.; Franke, L.; Posthumus, M.D.; van Heel, D.A.; van der Steege, G.; Radstake, T.R.D.J.; Barrera, P.; Roep, B.O.; Koeleman, B.P.C.; Wijmenga, C. Novel Association in Chromosome 4q27 Region with Rheumatoid Arthritis and Confirmation of Type 1 Diabetes Point to a General Risk Locus for Autoimmune Diseases. Am. J. Hum. Genet., 2007, 81, 1284-1288.

[178] Hinks, A.; Eyre, S.; Ke, X.; Barton, A.; Martin, P.; Flynn, E.; Packham, J.; Worthington, J.; Thomson, W. Association of the AFF3 gene and IL2/IL21 gene region with juvenile idiopathic arthritis. Genes Immun., 2010, 11, 194-198.

[179] Liu, Y.; Helms, C.; Liao, W.; Zaba, L.C.; Duan, S.; Gardner, J.; Wise, C.; Miner, A.; Malloy, M.J.; Pullinger, C.R.; Kane, J.P.; Saccone, S.; Worthington, J.; Bruce, I.; Kwok, P.; Menter, A.; Krueger, J.; Barton, A.; Saccone, N.L.; Bowcock, A.M. A Genome-Wide Association Study of Psoriasis and Psoriatic Arthritis Identifies New Disease Loci. PLoS Genet., 2008, 4, e1000041.

[180] Maiti, A.K.; Kim-Howard, X.; Viswanathan, P.; Guilln, L.; RojasVillarraga, A.; Deshmukh, H.; Direskeneli, H.; SaruhanDireskeneli, G.; Caas, C.; Tob+Ân, G.J.; Sawalha, A.H.; Cheravsky, A.C.; Anaya, J.M.; Nath, S.K. Confirmation of an association between rs6822844 at the I12GÇôI121 region and multiple autoimmune diseases: Evidence of a general susceptibility locus. Arthritis Rheum., 2010, 62, 323-329.

[181] Hollis-Moffatt, J.; Chen-Xu, M.; Topless, R.; Dalbeth, N.; Gow, P.; Harrison, A.; Highton, J.; Jones, P.; Nissen, M.; Smith, M.; van Rij, A.; Jones, G.; Stamp, L.; Merriman, T. Only one independent genetic association with rheumatoid arthritis within the KIAA1109TENR-IL2-IL21 locus in Caucasian sample sets: confirmation of association of rs6822844 with rheumatoid arthritis at a genomewide level of significance. Arthritis Res. Ther., 2010, 12, R116.

[182] Gregory, S.G.; Schmidt, S.; Seth, P.; Oksenberg, J.R.; Hart, J.; Prokop, A.; Caillier, S.J.; Ban, M.; Goris, A.; Barcellos, L.F.; Lincoln, R.; McCauley, J.L.; Sawcer, S.J.; Compston, D.A.S.; Dubois, B.; Hauser, S.L.; Garcia-Blanco, M.A.; Pericak-Vance, M.A.; Haines, J.L. Interleukin 7 receptor +- chain (IL7R) shows allelic and functional association with multiple sclerosis. Nat. Genet., 2007, 39, 1083-1091.

[183] Hafler, D.A.; Compston, A.; Sawcer, S.; Lander, E.S.; Daly, M.J.; De Jager, P.L.; De Bakker, P.I.W.; Gabriel, S.B.; Mirel, D.B.; Ivinson, A.J.; Pericak-Vance, M.A.; Gregory, S.G.; Rioux, J.D.; McCauley, J.L.; Haines, J.L.; Barcellos, L.F.; Cree, B.; Oksenberg, J.R.; Hauser, S.L. Risk alleles for multiple sclerosis identified by a genomewide study. N. Engl. J. Med., 2007, 357, 851-862.

[184] Hoffjan, S.; Akkad, D.A. The genetics of multiple sclerosis: An update 2010. Mol. Cell. Probes, 2010, 24, 237-243.

[185] Sutherland, A.; Davies, J.; Owen, C.J.; Vaikkakara, S.; Walker, C.; Cheetham, T.D.; James, R.A.; Perros, P.; Donaldson, P.T.; Cordell, H.J.; Quinton, R.; Pearce, S.H.S. Genomic polymorphism at the interferon-induced helicase (IFIH1) locus contributes to graves' disease susceptibility. J. Clin. Endocrinol. Metab., 2007, 92, 33383341.

[186] Penna-Martinez, M.; Ramos-Lopez, E.; Robbers, I.; Kahles, H.; Hahner, S.; Willenberg, H.; Reisch, N.; Seidl, C.; Segni, M.; Badenhoop, K. The rs1990760 polymorphism within the IFIH1 locus is not associated with Graves' disease, Hashimoto's thyroiditis and Addison's disease. BMC Med. Genet., 2009, 10, 126.

[187] Zhao, Z.F.; Cui, B.; Chen, H.Y.; Wang, S.; Li, I.; Gu, X.J.; Qi, L.; Li, X.Y.; Ning, G.; Zhao, Y.J. The A946T polymorphism in the interferon induced helicase gene does not confer susceptibility to GravesGÇÖ disease in Chinese population. Endocrine, 2007, 32, 143-147.

[188] Ban, Y.; Tozaki, T.; Taniyama, M.; Nakano, Y.; Ban, Y.; Hirano, T. Genomic polymorphism in the interferon-induced helicase (IFIH1) gene does not confer susceptibility to autoimmune thyroid disease in the Japanese population. Horm. Metab. Res., 2010, 42, 70-72.
[189] Smyth, D.J.; Cooper, J.D.; Bailey, R.; Field, S.; Burren, O.; Smink, L.J.; Guja, C.; Ionescu-Tirgoviste, C.; Widmer, B.; Dunger, D.B. Savage, D.A.; Walker, N.M.; Clayton, D.G.; Todd, J.A. A genomewide association study of nonsynonymous SNPs identifies a type 1 diabetes locus in the interferon-induced helicase (IFIH1) region. Nat. Genet., 2006, 38, 647-619.

[190] Jermendy, A.; Szatmári, I.; Laine, A.P.; Lukács, K.; Horváth, K.H.; Körner, A.; Madácsy, L.; Veijola, R.; Simell, O.; Knip, M.; Ilonen, J.; Hermann, R.; Finnish Paediatric Diabetes Registry; HUNT1DGENES Programme. The interferon-induced helicase IFIH1 Ala946Thr polymorphism is associated with type 1 diabetes in both the high-incidence Finnish and the medium-incidence Hungarian populations. Diabetologia, 2010, 53, 98-102.

[191] Martinez, A.; Santiago, J.L.; Cenit, M.C.; las Heras, V.; de la Calle, H.; Fernandez-Arquero, M.; Arroyo, R.; de la Concha, E.G.; Urcelay, E. IFIH1-GCA-KCNH7 locus: influence on multiple sclerosis risk. Eur. J. Hum. Genet., 2008, 16, 861-864.

[192] Enevold, C.; Oturai, A.B.; Sorensen, P.S.; Ryder, L.P.; KochHenriksen, N.; Bendtzen, K. Multiple sclerosis and polymorphisms of innate pattern recognition receptors TLR1-10, NOD1-2, DDX58, and IFIH1. J. Neuroimmunol., 2009, 212, 125-131.

[193] Martinez, A.; Varade, J.; Lamas, J.R.; Fernandez-Arquero, M. Jover, J.A.; de la Concha, E.G.; Fernandez-Gutięrrez, B.; Urcelay, E. Association of the IFIH1-GCA-KCNH7 chromosomal region with rheumatoid arthritis. Ann. Rheum. Dis., 2008, 67, 137-138.

[194] Marinou, I.; Montgomery, D.; Dickson, M.; Binks, M.; Moore, D.; Bax, D.; Wilson, A. The interferon induced with helicase domain 1 A946T polymorphism is not associated with rheumatoid arthritis Arthritis Res. Ther., 2007, 9, R40.

[195] Li, Y.H.; Liao, W.; Cargill, M.; Chang, M.; Matsunami, N.; Feng, B.J.; Poon, A.; Callis-Duffin, K.P.; Catanese, J.J.; Bowcock, A.M.; Leppert, M.F.; Kwok, P.Y.; Krueger, G.G.; Begovich, A.B. Carriers of Rare Missense Variants in IFIH1 Are Protected from Psoriasis. J. Invest. Dermatol., 2010, 130, 2768-2772.

[196] Gateva, V.; Sandling, J.K.; Hom, G.; Taylor, K.E.; Chung, S.A.; Sun, X.; Ortmann, W.; Kosoy, R.; Ferreira, R.C.; Nordmark, G.; Gunnarsson, I.; Svenungsson, E.; Padyukov, L.; Sturfelt, G.; Jonsen, A.; Bengtsson, A.A.; Rantapaa-Dahlqvist, S.; Baechler, E.C.; Brown, E.E.; Alarcon, G.S.; Edberg, J.C.; Ramsey-Goldman, R.; McGwin, G.; Reveille, J.D.; Vila, L.M.; Kimberly, R.P.; Manzi, S.; Petri, M.A.; Lee, A.; Gregersen, P.K.; Seldin, M.F.; Ronnblom, L.; Criswell, L.A.; Syvanen, A.C.; Behrens, T.W.; Graham, R.R. A large-scale replication study identifies TNIP1, PRDM1, JAZF1, UHRF1BP1 and IL10 as risk loci for systemic lupus erythematosus. Nat. Genet., 2009, 41, 1228-1233.

[197] Nejentsev, S.; Walker, N.; Riches, D.; Egholm, M.; Todd, J.A. Rare Variants of IFIH1, a Gene Implicated in Antiviral Responses, Protect Against Type 1 Diabetes. Science, 20091167728.

[198] Chistiakov, D.A. Interferon Induced with Helicase C Domain 1 (IFIH1) and Virus-Induced Autoimmunity: A Review. Viral Immunol., 2010, 23, 3-15.

[199] Shigemoto, T.; Kageyama, M.; Hirai, R.; Zheng, J.; Yoneyama, M.; Fujita, T. Identification of Loss of Function Mutations in Human Genes Encoding RIG-I and MDA5. J. Biol. Chem., 2009, 284, 13348-13354.

[200] Liu, S.; Wang, H.; Jin, Y.; Podolsky, R.; Reddy, M.P.L.; Pedersen, J.; Bode, B.; Reed, J.; Steed, D.; Anderson, S.; Yang, P.; Muir, A.; Steed, L.; Hopkins, D.; Huang, Y.; Purohit, S.; Wang, C.Y.; Steck, A.K.; Montemari, A.; Eisenbarth, G.; Rewers, M.; She, J.X. IFIH1 polymorphisms are significantly associated with type 1 diabetes and IFIH1 gene expression in peripheral blood mononuclear cells Hum. Mol. Genet., 2009, 18, 358-365.

[201] Downes, K.; Pekalski, M.; Angus, K.L.; Hardy, M.; Nutland, S.; Smyth, D.J.; Walker, N.M.; Wallace, C.; Todd, J.A. Reduced expression of IFIH1 is protective for type 1 diabetes. PLOS ONE, 2010, 5, e12646.

[202] Zouk, H.; Marchand, L.; Polychronakos, C. Study of transcriptional effects in Cis at the IFIH1 locus. PLOS ONE, 2010, 5, e11564.

[203] Ma, C.; Staudt, L.M. LAF-4 encodes a lymphoid nuclear protein with transactivation potential that is homologous to AF-4, the gene fused to MLL in $\mathrm{t}(4 ; 11)$ leukemias. Blood, 1996, 87, 734-745.

[204] Barton, A.; Eyre, S.; Ke, X.; Hinks, A.; Bowes, J.; Flynn, E.; Martin, P.; YEAR Consortium; BIRAC Consortium; Wilson, A.G.; Morgan, A.W.; Emery, P.; Steer, S.; Hocking, L.J.; Reid, D.M.; Harrison, P.; Wordsworth, P.; Thomson, W.; Worthington, J. Identification of AF4/FMR2 family, member 3 (AFF3) as a novel 
rheumatoid arthritis susceptibility locus and confirmation of two further pan-autoimmune susceptibility genes. Hum. Mol. Genet., 2009, 18, 2518-2522.

[205] Bottino, C.; Castriconi, R.; Pende, D.; Rivera, P.; Nanni, M.; Carnemolla, B.; Cantoni, C.; Grassi, J.; Marcenaro, S.; Reymond, N.; Vitale, M.; Moretta, L.; Lopez, M.; Moretta, A. Identification of PVR (CD155) and Nectin-2 (CD112) as cell surface ligands for the human DNAM-1 (CD226) activating molecule. J. Exp. Med., 2003, 198, 557-567.

[206] Shibuya, A.; Campbell, D.; Hannum, C.; Yssel, H.; Franz-Bacon, K.; McClanahan, T.; Kitamura, T.; Nicholl, J.; Sutherland, G.R.; Lanier, L.L.; Phillips, J.H. DNAM-1, A novel adhesion molecule involved in the cytolytic function of $\mathrm{T}$ lymphocytes. Immunity, 1996, 4, 573-581.

[207] Xu, Z.; Jin, B. A novel interface consisting of homologous immunoglobulin superfamily members with multiple functions. Cell. Mol. Immunol., 2010, 7, 11-19.

[208] Hafler, J.P.; Maier, L.M.; Cooper, J.D.; Plagnol, V.; Hinks, A.; Simmonds, M.J.; Stevens, H.E.; Walker, N.M.; Healy, B.; Howson, J.M.M.; Maisuria, M.; Duley, S.; Coleman, G.; Gough, S.C.L.; Worthington, J.; Kuchroo, V.K.; Wicker, L.S.; Todd, J.A. CD226 Gly307Ser association with multiple autoimmune diseases. Genes Immun., 2008.

[209] Lofgren, S.E.; Delgado-Vega, A.M.; Gallant, C.J.; Saínchez, E.; Frostegard, J.; Truedsson, L.; Ramon Garrido, E.; Sabio, J.M.; Gonzaílez-Escribano, M.F.; Pons-Estel, B.A.; D'Alfonso, S.; Witte, T.; Lauwerys, B.R.; Endreffy, E.; Kovícs, L.+.; Vasconcelos, C.; Martins da Silva, B.; Marten, J.; Alarc-n-Riquelme, M.E.; Kozyrev, S.V. A 3GÇ--untranslated region variant is associated with impaired expression of CD226 in T and natural killer T cells and is associated with susceptibility to systemic lupus erythematosus. Arthritis Rheum., 2010, 62, 3404-3414.

[210] Wieczorek, S.; Hoffjan, S.; Chan, A.; Rey, L.; Harper, L.; Fricke, H.; Holle, J.U.; Gross, W.L.; Epplen, J.T.; Lamprecht, P. Novel association of the CD226 (DNAM-1) Gly307Ser polymorphism in Wegener's granulomatosis and confirmation for multiple sclerosis in German patients. Genes Immun., 2009, 10, 591-595.

[211] Dieude, P.; Guedj, M.; Truchetet, M.E.; Wipff, J.; Revillod, L.; Riemekasten, G.; Matucci-Cerinic, M.; Melchers, I.; Hachulla, E.; Airo, P.; Diot, E.; Hunzelmann, N.; Mouthon, L.; Cabane, J.; Cracowski, J.L.; Riccieri, V.; Distler, J.; Amoura, Z.; Valentini, G.; Camaraschi, P.; Tarner, I.; Frances, C.; Carpentier, P.; Brembilla, N.C.; Meyer, O.; Kahan, A.; Chizzolini, C.; Boileau, C.; Allanore, Y. Association of the CD226 Ser307 variant with systemic sclerosis: Evidence of a contribution of costimulation pathways in systemic sclerosis pathogenesis. Arthritis Rheum., 2011, 63, 10971105 .

[212] Genome-wide association study of 14,000 cases of seven common diseases and 3,000 shared controls. Nature, 2007, 447, 661-678.

[213] Franke, A.; Balschun, T.; Karlsen, T.H.; Hedderich, J.; May, S.; Lu, T.; Schuldt, D.; Nikolaus, S.; Rosenstiel, P.; Krawczak, M.; Schreiber, S. Replication of signals from recent studies of Crohn's disease identifies previously unknown disease loci for ulcerative colitis. Nat. Genet., 2008, 40, 713-715.

[214] Thompson, S.D.; Sudman, M.; Ramos, P.S.; Marion, M.C.; Ryan, M.; Tsoras, M.; Weiler, T.; Wagner, M.; Keddache, M.; Haas, J.P.; Mueller, C.; Prahalad, S.; Bohnsack, J.; Wise, C.A.; Punaro, M.; Zhang, D.; Rose, C.D.; Comeau, M.E.; Divers, J.; Glass, D.N.; Langefeld, C.D. The susceptibility loci juvenile idiopathic arthritis shares with other autoimmune diseases extend to PTPN2, COG6, and ANGPT1. Arthritis Rheum., 2010, 62, 3265-3276.

[215] Smyth, D.J.; Plagnol, V.; Walker, N.M.; Cooper, J.D.; Downes, K.; Yang, J.H.M.; Howson, J.M.M.; Stevens, H.; McManus, R.; Wijmenga, C.; Heap, G.A.; Dubois, P.C.; Clayton, D.G.; Hunt, K.A.; van Heel, D.A.; Todd, J.A. Shared and distinct genetic variants in type 1 diabetes and celiac disease. N. Engl. J. Med., 2008, 359, 2767-2777.

[216] Doody, K.M.; Bourdeau, A.; Tremblay, M.L. T-cell protein tyrosine phosphatase is a key regulator in immune cell signaling: lessons from the knockout mouse model and implications in human disease. Immunol. Rev., 2009, 228, 325-341.

[217] Ban, Y.; Taniyama, M.; Ban, Y. Vitamin D receptor gene polymorphism is associated with Graves' disease in the Japanese population. J. Clin. Endocrinol. Metab., 2000, 85, 4639-4643.
[218] Ban, Y.; Ban, Y.; Taniyama, M.; Katagiri, T. Vitamin D receptor initiation codon polymorphism in Japanese patients with Graves' disease. Thyroid, 2000, 10, 475-480.

[219] Huber, A.K.; Jacobson, E.M.; Jazdzewski, K.; Concepcion, E.S.; Tomer, Y. Interleukin (IL)-23 receptor is a major susceptibility gene for Graves' ophthalmopathy: the IL-23/T-helper 17 axis extends to thyroid autoimmunity. J. Clin. Endocrinol. Metab., 2008, 93, 1077-1081.

[220] Kisiel, B.; Bednarczuk, T.; Kostrzewa, G.; Kosinska, J.; kiewicz, P.; Plazinska, M.T.; Bar-Andziak, E.; Krolicki, L.; Krajewski, P.; Ploski, R. Polymorphism of the oestrogen receptor beta gene (ESR2) is associated with susceptibility to Graves' disease. Clin. Endocrinol. (Oxf), 2008, 68, 429-434.

[221] Kisiel, B.M.; Kosinska, J.; Wierzbowska, M.; Rutkowska-Sak, L.; Musiej-Nowakowska, E.; Wudarski, M.; Olesinska, M.; Krajewski, P.; Lacki, J.; Rell-Bakalarska, M.; Jagodzinski, P.P.; Tlustochowicz, W.; Ploski, R. Differential association of juvenile and adult systemic lupus erythematosus with genetic variants of oestrogen receptors alpha and beta. Lupus, 2011, 20, 85-89.

[222] Putnik, M.; Zhao, C.; Gustafsson, J.A.; Dahlman-Wright, K. Effects of two common polymorphisms in the 3 ' untranslated regions of estrogen receptor beta on mRNA stability and translatability. BMC Genetics, 2009, 10.

[223] Kurylowicz, A.; Hiromatsu, Y.; Jurecka-Lubieniecka, B.; Kula, D.; Kowalska, M.; Ichimura, M.; Koga, H.; Kaku, H.; Bar-Andziak, E.; Nauman, J.; Jarzab, B.; Ploski, R.; Bednarczuk, T. Association of NFKB1 -94ins/del ATTG promoter polymorphism with susceptibility to and phenotype of Graves' disease. Genes Immun., 2007, 8, 532-538.

[224] Karban, A.S.; Okazaki, T.; Panhuysen, C.I.M.; Gallegos, T.; Potter, J.J.; Bailey-Wilson, J.E.; Silverberg, M.S.; Duerr, R.H.; Cho, J.H.; Gregersen, P.K.; Wu, Y.; Achkar, J.P.; Dassopoulos, T.; Mezey, E.; Bayless, T.M.; Nouvet, F.J.; Brant, S.R. Functional annotation of a novel NFKB1 promoter polymorphism that increases risk for ulcerative colitis. Hum. Mol. Genet., 2004, 13, 35-45.

[225] Zou, Y.F.; Wang, F.; Feng, X.L.; Tao, J.H.; Zhu, J.M.; Pan, F.M.; $\mathrm{Su}, \mathrm{H}$. Association of NFKB1 -94ins/delATTG promoter polymorphism with susceptibility to autoimmune and inflammatory diseases: a meta-analysis. Tissue Antigens, 2011, 77, 9-17.

[226] Baldwin, A.S. Series Introduction: The transcription factor NFkappaB and human disease. J. Clin. Invest., 2001, 107, 3-6.

[227] Brown, C.J. Skewed X-chromosome inactivation: cause or consequence? J. Natl. Cancer Inst., 1999, 91, 304-305.

[228] Kristiansen, M.; Knudsen, G.P.S.; Bathum, L.; Naumova, A.K.; Sorensen, T.I.A.; Brix, T.H.; Svendsen, A.J.; Christensen, K.; Kyvik, K.O.; Ørstavik, K.H. Twin study of genetic and aging effects on X chromosome inactivation. Eur. J. Hum. Genet., 2005 , 13, 599-606.

[229] Christensen, K.; Kristiansen, M.; Hagen-Larsen, H.; Skylthe, A.; Bathum, L.; Jeune, B.; Andersen-Ranberg, K.; Vaupel, J.W.; Ørstavik, K.H. X-linked genetic factors regulate hematopoietic stem-cell kinetics in females. Blood, 2000, 95, 2449-2451.

[230] Vickers, M.A.; McLeod, E.; Spector, T.D.; Wilson, I.J. Assessment of mechanism of acquired skewed $\mathrm{X}$ inactivation by analysis of twins. Blood, 2001, 97, 1274-1281.

[231] Naumova, A.K.; Olien, L.; Bird, L.M.; Smith, M.; Verner, A.E.; Leppert, M.; Morgan, K.; Sapienza, C. Genetic mapping of Xlinked loci involved in skewing of $\mathrm{X}$ chromosome inactivation in the human. Eur. J. Hum. Genet., 1998, 6, 552-562.

[232] Sharp, A.; Robinson, D.; Jacobs, P. Age- and tissue-specific variation of $\mathrm{X}$ chromosome inactivation ratios in normal women. Hum.Genet., 2000, 107, 343-349.

[233] Brix, T.H.; Knudsen, G.P.; Kristiansen, M.; Kyvik, K.O.; Orstavik, K.H.; Hegedus, L. High frequency of skewed X-chromosome inactivation in females with autoimmune thyroid disease: a possible explanation for the female predisposition to thyroid autoimmunity. J. Clin. Endocrinol. Metab., 2005, 90, 5949-5953.

[234] Ozcelik, T.; Uz, E.; Akyerli, C.B.; Bagislar, S.; Mustafa, C.A.; Gursoy, A.; Akarsu, N.; Toruner, G.; Kamel, N.; Gullu, S. Evidence from autoimmune thyroiditis of skewed X-chromosome inactivation in female predisposition to autoimmunity. Eur. J. Hum. Genet., 2006, 14, 791-797.

[235] Yin, X.; Latif, R.; Tomer, Y.; Davies, T.F. Thyroid epigenetics: X chromosome inactivation in patients with autoimmune thyroid disease. Ann. N. Y. Acad. Sci., 2007, 1110, 193-200. 
[236] Chabchoub, G.; Uz, E.; Maalej, A.; Mustafa, C.A.; Rebai, A.; Mnif, M.; Bahloul, Z.; Farid, N.R.; Ozcelik, T.; Ayadi, H. Analysis of skewed X-chromosome inactivation in females with rheumatoid arthritis and autoimmune thyroid diseases. Arthritis Res. Ther., 2009, 11, R106.

[237] Kast, R.E. Hypothesis - Predominance of Autoimmune and Rheumatic Diseases in Females. J. Rheum., 1977, 4, 288-292.

[238] Stewart, J.J. The female X-inactivation mosaic in systemic lupus erythematosus. Immunol. Today, 1998, 19, 352-357.

[239] Ozcelik, T. X chromosome inactivation and female predisposition to autoimmunity. Clin. Rev. Allergy Immunol., 2008, 34, 348-351.

[240] Chitnis, S.; Monteiro, J.; Glass, D.; Apatoff, B.; Salmon, J.; Concannon, P.; Gregersen, P.K. The role of X-chromosome inactivation in female predisposition to autoimmunity. Arthritis Res., 2000, 2, 399-406.

[241] Knudsen, G.P.S.; Harbo, H.F.; Smestad, C.; Celius, E.G.; Akesson, E.; Oturai, A.; Ryder, L.P.; Spurkland, A.; Orstavik, K.H. X chromosome inactivation in females with multiple sclerosis. Eur. J. Neurol., 2007, 14, 1392-1396.

[242] Miozzo, M.; Selmi, C.; Gentilin, B.; Grati, F.R.; Sirchia, S.; Oertelt, S.; Zuin, M.; Gershwin, M.E.; Podda, M.; Invernizzi, P. Preferential $\mathrm{X}$ chromosome loss but random inactivation characterize primary biliary cirrhosis. Hepatology, 2007, 46, 456462 .

[243] Smith-Bouvier, D.L.; Divekar, A.A.; Sasidhar, M.; Du, S.; TiwariWoodruff, S.K.; King, J.K.; Arnold, A.P.; Singh, R.R.; Voskuhl, R.R. A role for sex chromosome complement in the female bias in autoimmune disease. J. Exp. Med., 2008, 205, 1099-1108.

[244] Brix, T.H.; Hansen, P.S.; Kyvik, K.O.; Hegedus, L. Preliminary evidence of a noncausal association between the X-chromosome inactivation pattern and thyroid autoimmunity: a twin study. Eur. $J$. Hum. Genet., 2009, 18, 254-257.

[245] Elsheikh, M.; Wass, J.A.; Conway, G.S. Autoimmune thyroid syndrome in women with Turner's syndrome--the association with karyotype. Clin. Endocrinol. (Oxf), 2001, 55, 223-226.

[246] Invernizzi, P.; Miozzo, M.; Selmi, C.; Persani, L.; Battezzati, P.M.; Zuin, M.; Lucchi, S.; Meroni, P.L.; Marasini, B.; Zeni, S.; Watnik, M.; Grati, F.R.; Simoni, G.; Gershwin, M.E.; Podda, M. X chromosome monosomy: a common mechanism for autoimmune diseases. J. Immunol., 2005, 175, 575-578.

[247] Barbesino, G.; Tomer, Y.; Concepcion, E.S.; Davies, T.F.; Greenberg, D.A. Linkage analysis of candidate genes in autoimmune thyroid disease. II. Selected gender-related genes and the X-chromosome. International consortium for the genetics of autoimmune thyroid disease. J. Clin. Endocrinol. Metab., 1998, 83, 3290-3295

[248] Imrie, H.; Vaidya, B.; Perros, P.; Kelly, W.F.; Toft, A.D.; Young, E.T.; Kendall-Taylor, P.; Pearce, S.H. Evidence for a Graves' disease susceptibility locus at chromosome Xp11 in a United Kingdom population. J. Clin. Endocrinol. Metab., 2001, 86, 626630 .

[249] Bianchi, D.W.; Zickwolf, G.K.; Weil, G.J.; Sylvester, S.; DeMaria, M.A. Male fetal progenitor cells persist in maternal blood for as long as 27 years postpartum. PNAS, 1996, 93, 705-708.

[250] Kennedy, R.L.; Malabu, U.H.; Jarrod, G.; Nigam, P.; Kannan, K.; Rane, A. Thyroid function and pregnancy: Before, during and beyond. J. Obstet. Gynaecol., 2010, 30, 774-783.

[251] Ando, T.; Davies, T.F. Postpartum Autoimmune Thyroid Disease: The Potential Role of Fetal Microchimerism. J. Clin. Endocrinol. Metab., 2003, 88, 2965-2971.

[252] Srivatsa, B.; Srivatsa, S.; Johnson, K.L.; Samura, O.; Lee, S.L.; Bianchi, D.W. Microchimerism of presumed fetal origin in thyroid specimens from women: a case-control study. Lancet, 2001, 358, 2034-2038.

[253] Klintschar, M.; Schwaiger, P.; Mannweiler, S.; Regauer, S.; Kleiber, M. Evidence of Fetal Microchimerism in Hashimoto's Thyroiditis. J. Clin. Endocrinol. Metab., 2001, 86, 2494-2498.

[254] Klintschar, M.; Immel, U.D.; Kehlen, A.; Schwaiger, P.; Mustafa, T.; Mannweiler, S.; Regauer, S.; Kleiber, M.; Hoang-Vu, C. Fetal microchimerism in Hashimoto's thyroiditis: a quantitative approach. Eur. J. Endocrinol., 2006, 154, 237-241.

[255] Ando, T.; Imaizumi, M.; Graves, P.N.; Unger, P.; Davies, T.F. Intrathyroidal Fetal Microchimerism in Graves Disease. J. Clin. Endocrinol. Metab., 2002, 87, 3315-3320.

[256] Renne, C.; Ramos Lopez, E.; Steimle-Grauer, S.A.; Ziolkowski, P.; Pani, M.A.; Luther, C.; Holzer, K.; Encke, A.; Wahl, R.A.;
Bechstein, W.O.; Usadel, K.H.; Hansmann, M.L.; Badenhoop, K. Thyroid Fetal Male Microchimerisms in Mothers with Thyroid Disorders: Presence of Y-Chromosomal Immunofluorescence in Thyroid-Infiltrating Lymphocytes Is More Prevalent in HashimotoGÇÖs Thyroiditis and GravesGÇÖ Disease Than in Follicular Adenomas. J. Clin. Endocrinol. Metab., 2004, 89, 58105814.

[257] Brix, T.H.; Hansen, P.S.; Kyvik, K.O.; Hegedus, L. Aggregation of thyroid autoantibodies in twins from opposite-sex pairs suggests that microchimerism may play a role in the early stages of thyroid autoimmunity. J. Clin. Endocrinol. Metab., 2009, 94, 4439-4443.

[258] Imaizumi, M.; Pritsker, A.; Unger, P.; Davies, T.F. Intrathyroidal Fetal Microchimerism in Pregnancy and Postpartum. Endocrinology, 2002, 143, 247-253.

[259] Ando, T.; Davies, T.F. Self-recognition and the role of fetal microchimerism. Best Pract. Res. Clin. Endocrinol. Metab., 2004, 18, 197-211.

[260] Khosrotehrani, K.; Johnson, K.L.; Cha, D.H.; Salomon, R.N.; Bianchi, D.W. Transfer of fetal cells with multilineage potential to maternal tissue. JAMA, 2004, 292, 75-80.

[261] Wang, Y.; Iwatani, H.; Ito, T.; Horimoto, N.; Yamato, M.; Matsui, I.; Imai, E.; Hori, M. Fetal cells in mother rats contribute to the remodeling of liver and kidney after injury. Biochem. Biophys. Res. Commun., 2004, 325, 961-967.

[262] Khosrotehrani, K.; Reyes, R.R.; Johnson, K.L.; Freeman, R.B.; Salomon, R.N.; Peter, I.; Stroh, H.; Guegan, S.; Bianchi, D.W. Fetal cells participate over time in the response to specific types of murine maternal hepatic injury. Hum. Reprod., 2007, 22, 654-661.

[263] Bou-Gharios, G.; Amin, F.; Hill, P.; Nakamura, H.; Maxwell, P.; Fisk, N.M. Microchimeric fetal cells are recruited to maternal kidney following injury and activate collagen type i transcription. Cells Tissues Organs, 2011, 193, 379-392.

[264] O'Donoghue, K.; Sultan, H.A.; Ai-Allaf, F.A.; Anderson, J.R.; Wyatt-Ashmead, J.; Fisk, N.M. Microchimeric fetal cells cluster at sites of tissue injury in lung decades after pregnancy. Reprod. Biomed. Online, 2008, 16, 382-390.

[265] Friedrich, N.; Schwarz, S.; Thonack, J.; John, U.; Wallaschofski, H.; Volzke, H. Association between parity and autoimmune thyroiditis in a general female population. Autoimmunity, 2008, 41, 174-180.

[266] Phillips, D.I.; Lazarus, J.H.; Butland, B.K. The influence of pregnancy and reproductive span on the occurrence of autoimmune thyroiditis. Clin. Endocrinol. (Oxf), 1990, 32, 301-306.

[267] Walsh, J.P.; Bremner, A.P.; Bulsara, M.K.; OGÇÖLeary, P.; Leedman, P.J.; Feddema, P.; Michelangeli, V. Parity and the risk of autoimmune thyroid disease: a community-based study. J. Clin. Endocrinol. Metab., 2005, 90, 5309-5312.

[268] Pedersen, I.B.; Laurberg, P.; Knudsen, N.; Jorgensen, T.; Perrild, H.; Ovesen, L.; Rasmussen, L.B. Lack of association between thyroid autoantibodies and parity in a population study argues against microchimerism as a trigger of thyroid autoimmunity. Eur. J. Endocrinol., 2006, 154, 39-45.

[269] Sgarbi, J.A.; Kasamatsu, T.S.; Matsumura, L.K.; Maciel, R.M.B. Parity is not related to autoimmune thyroid disease in a populationbased study of japanese-brazilians. Thyroid, 2010, 20, 1151-1156.

[270] Fugazzola, L.; Cirello, V.; Beck-Peccoz, P. Fetal microchimerism as an explanation of disease. Nat. Rev. Endocrinol., 2011, 7, 89-97.

[271] Brix, T.H.; Hegedus, L. Twins as a tool for evaluating the influence of genetic susceptibility in thyroid autoimmunity. Ann. Endocrinol. (Paris), 2011, 72, 103-107.

[272] Bednarczuk, T.; Gopinath, B.; Ploski, R.; Wall, J.R. Susceptibility genes in Graves' ophthalmopathy: searching for a needle in a haystack? Clin. Endocrinol. (Oxf), 2007, 67, 3-19.

[273] Kim, K.W.; Park, Y.J.; Kim, T.Y.; Park, d.J.; Park, K.S.; Cho, B.Y. Susceptible alleles of the CD40 and CTLA-4 genes are not associated with the relapse after antithyroid withdrawal in Graves' disease. Thyroid, 2007, 17, 1229-1234.

[274] Badenhoop, K.; Donner, H.; Braun, J.; Siegmund, T.; Rau, H.; Usadel, K.H. Genetic markers in diagnosis and prediction of relapse in Graves' disease. Exp. Clin. Endocrinol. Diabetes, 1996, 104 Suppl 4, 98-100.

[275] Bednarczuk, T.; Hiromatsu, Y.; Fukutani, T.; Jazdzewski, K.; Miskiewicz, P.; Osikowska, M.; Nauman, J. Association of cytotoxic T-lymphocyte-associated antigen-4 (CTLA-4) gene polymorphism and non-genetic factors with Graves' 
ophthalmopathy in European and Japanese populations. Eur. J. Endocrinol., 2003, 148, 13-18.

[276] Siegmund, T.; Usadel, K.H.; Donner, H.; Braun, J.; Walfish, P.G.; Badenhoop, K. Interferon-gamma gene microsatellite polymorphisms in patients with Graves' disease. Thyroid, 1998, 8 , 1013-1017.

[277] Kamizono, S.; Hiromatsu, Y.; Seki, N.; Bednarczuk, T.; Matsumoto, H.; Kimura, A.; Itoh, K. A polymorphism of the 5' flanking region of tumour necrosis factor alpha gene is associated with thyroid-associated ophthalmopathy in Japanese. Clin. Endocrinol. $(O x f), 2000,52,759-764$.

[278] Bednarczuk, T.; Hiromatsu, Y.; Seki, N.; Ploski, R.; Fukutani, T.; Kurylowicz, A.; Jazdzewski, K.; Chojnowski, K.; Itoh, K.; Nauman, J. Association of tumor necrosis factor and human leukocyte antigen DRB1 alleles with Graves' ophthalmopathy. Hum. Immunol., 2004, 65, 632-639.

[279] Khalilzadeh, O.; Anvari, M.; Esteghamati, A.; Mahmoudi, M.; Tahvildari, M.; Rashidi, A.; Khosravi, F.; Amirzargar, A. Graves' ophthalmopathy and gene polymorphisms in interleukin-1alpha, interleukin-1beta, interleukin-1 receptor and interleukin-1 receptor antagonist. Clin. Experiment. Ophthalmol., 2009, 37, 614-619.

[280] Gu, X.J.; Cui, B.; Zhao, Z.F.; Chen, H.Y.; Li, X.Y.; Wang, S.; Ning, G.; Zhao, Y.J. Association of the interleukin (IL)-16 gene polymorphisms with Graves' disease. Clin. Immunol., 2008, 127, 298-302.

[281] Vaidya, B.; Oakes, E.J.; Imrie, H.; Dickinson, A.J.; Perros, P.; Kendall-Taylor, P.; Pearce, S.H. CTLA4 gene and Graves' disease: association of Graves' disease with the CTLA4 exon 1 and intron 1 polymorphisms, but not with the promoter polymorphism. Clin. Endocrinol. (Oxf), 2003, 58, 732-735.

[282] Han, S.Z.; Zhang, S.H.; Li, R.; Zhang, W.Y.; Li, Y. The common $318 \mathrm{C} / \mathrm{T}$ polymorphism in the promoter region of CTLA4 gene is associated with reduced risk of ophthalmopathy in Chinese Graves' patients. Int. J. Immunogenet., 2006, 33, 281-287.

[283] Kretowski, A.; Wawrusiewicz, N.; Mironczuk, K.; Mysliwiec, J.; Kretowska, M.; Kinalska, I. Intercellular adhesion molecule 1 gene polymorphisms in Graves' disease. J. Clin. Endocrinol. Metab., 2003, 88 , 4945-4949.

[284] Syed, A.A.; Simmonds, M.J.; Brand, O.J.; Franklyn, J.A.; Gough, S.C.; Heward, J.M. Preliminary evidence for interaction of PTPN12 polymorphism with TSHR genotype and association with Graves' ophthalmopathy. Clin. Endocrinol. (Oxf), 2007, 67, 663667.
[285] Liao, W.L.; Chen, R.H.; Lin, H.J.; Liu, Y.H.; Chen, W.C.; Tsai, Y.; Wan, L.; Tsai, F.J. Toll-like receptor gene polymorphisms are associated with susceptibility to Graves' ophthalmopathy in Taiwan males. BMC Med. Genet., 2010, 11, 154.

[286] Liao, W.L.; Chen, R.H.; Lin, H.J.; Liu, Y.H.; Chen, W.C.; Tsai, Y.; Wan, L.; Tsai, F.J. The association between polymorphisms of B7 molecules (CD80 and CD86) and Graves' ophthalmopathy in a Taiwanese population. Ophthalmology, 2011, 118, 553-557.

[287] Lavard, L.; Madsen, H.O.; Perrild, H.; Jacobsen, B.B.; Svejgaard, A. HLA class II associations in juvenile Graves' disease: indication of a strong protective role of the DRB1*0701,DQA1*0201 haplotype. Tissue Antigens, 1997, 50, 639-641.

[288] Kinjo, Y.; Takasu, N.; Komiya, I.; Tomoyose, T.; Takara, M.; Kouki, T.; Shimajiri, Y.; Yabiku, K.; Yoshimura, H. Remission of Graves' hyperthyroidism and A/G polymorphism at position 49 in exon 1 of cytotoxic T lymphocyte-associated molecule-4 gene. $J$. Clin. Endocrinol. Metab., 2002, 87, 2593-2596.

[289] Kimura, H.; Kato, Y.; Shimizu, S.; Takano, K.; Sato, K. Association of polymorphism at position 49 in exon 1 of the cytotoxic T-lymphocyte-associated factor 4 gene with Graves' disease refractory to medical treatment, but not with amiodaroneassociated thyroid dysfunction. Thyroid, 2009, 19, 975-981.

[290] Wang, P.W.; Chen, I.Y.; Liu, R.T.; Hsieh, C.J.; Hsi, E.; Juo, S.H Cytotoxic T lymphocyte-associated molecule-4 gene polymorphism and hyperthyroid Graves' disease relapse after antithyroid drug withdrawal: a follow-up study. J. Clin. Endocrinol. Metab., 2007, 92, 2513-2518.

[291] Bruck, P.; Bartsch, W.; Sadet, D.; Penna-Martinez, M.; Kurylowicz, A.; Bednarczuk, T.; Robbers, I.; Paunkovic, J.; Bohme, A.; Badenhoop, K.; Ramos-Lopez, E. A CXC motif ligand 10 polymorphism as a marker to predict severity of Graves' disease. Thyroid, 2010, 20, 343-345.

[292] Zaletel, K.; Krhin, B.; Gaberscek, S.; Pirnat, E.; Hojker, S. The influence of the exon 1 polymorphism of the cytotoxic $\mathrm{T}$ lymphocyte antigen 4 gene on thyroid antibody production in patients with newly diagnosed Graves' disease. Thyroid, 2002, 12, 373-376

[293] Inoue, N.; Watanabe, M.; Nanba, T.; Wada, M.; Akamizu, T.; Iwatani, Y. Involvement of functional polymorphisms in the TNFA gene in the pathogenesis of autoimmune thyroid diseases and production of anti-thyrotropin receptor antibody. Clin. Exp. Immunol., 2009, 156, 199-204. 